\title{
Design of aluminium alloy beams at elevated temperatures
}

DOI:

10.1016/j.tws.2019.03.052

\section{Document Version}

Accepted author manuscript

Link to publication record in Manchester Research Explorer

\section{Citation for published version (APA):}

Su, M., Zhang, Y., \& Young, B. (2019). Design of aluminium alloy beams at elevated temperatures. Thin-Walled Structures, 140, 506-515. https://doi.org/10.1016/j.tws.2019.03.052

\section{Published in:}

Thin-Walled Structures

\section{Citing this paper}

Please note that where the full-text provided on Manchester Research Explorer is the Author Accepted Manuscript or Proof version this may differ from the final Published version. If citing, it is advised that you check and use the publisher's definitive version.

\section{General rights}

Copyright and moral rights for the publications made accessible in the Research Explorer are retained by the authors and/or other copyright owners and it is a condition of accessing publications that users recognise and abide by the legal requirements associated with these rights.

\section{Takedown policy}

If you believe that this document breaches copyright please refer to the University of Manchester's Takedown Procedures [http://man.ac.uk/04Y6Bo] or contact uml.scholarlycommunications@manchester.ac.uk providing relevant details, so we can investigate your claim.

\section{OPEN ACCESS}


Su, M.N., Zhang, Y. \& Young, B., (2019), "Design of aluminium alloy beams at elevated temperatures", Thin-walled structures. 140: 506-515.

\title{
Design of aluminium alloy beams at elevated temperatures
}

\author{
Mei-Ni Su ${ }^{1 *}$, Yu Zhang ${ }^{1}$ and Ben Young ${ }^{2}$ \\ ${ }^{1}$ School of Mechanical, Aerospace and Civil Engineering, University of Manchester, Manchester, \\ UK. Email: meini.su@manchester.ac.uk \\ ${ }^{2}$ Department of Civil and Environmental Engineering, The Hong Kong Polytechnic University, \\ Hong Kong, China (Formerly, Department of Civil Engineering, The University of Hong Kong, \\ Pokfulam Road, Hong Kong, China)
}

\begin{abstract}
The material properties of aluminium alloys could be affected significantly as temperature rises. The present study aims to investigate the behaviour of aluminium alloy beams at elevated temperatures using finite element analyses. The newly developed numerical model was validated against a total of eight square hollow section beams subjected to three-point bending tests at elevated temperatures. The validated model was used to generate 120 numerical results in the parametric study. Three key parameters were considered, including cross-section slenderness ranging from 8 to 38 , temperatures ranging from $24^{\circ} \mathrm{C}$ to $600^{\circ} \mathrm{C}$ and two aluminium alloys (6061T6 and 6063-T5). Thus, a data pool containing a total of 128 experimental and numerical results was formed. The appropriateness of the design rules in the American Aluminium Design Manual, the Australian/New Zealand Standard, Eurocode 9 and the continuous strength method (CSM) for aluminium alloy beams at elevated temperature are assessed against the newly generated data pool. In comparison, the design strengths predicted by the four design methods are generally conservative, whereas the CSM approach is found to be the most accurate and consistent throughout the full temperature range. Additionally, reliability analysis has also been conducted to evaluate the reliability level of the aforementioned design methods for aluminium alloy beams at elevated temperatures.
\end{abstract}

Keywords: Aluminium alloys; Beams; Elevated temperatures; Flexural design; Numerical study

\section{Introduction}

Aluminium alloys are used in construction industry widely for its high strength-to-weight ratio, 
ease of fabrication, good plasticity and corrosion-resistant. Aluminium alloy members are manufactured by extrusion and pultrusion, which enables the production of more complex shapes. This can be particularly beneficial for enhancing resistance to local buckling through, for example, the addition of internal stiffeners. A number of studies [1-5] have investigated the flexural behaviour and proposed the design methods of aluminium alloy thin-walled members with stiffeners. An urgent concern in the structural design of aluminium alloy members is the safety at high temperatures or fire conditions, since the material properties of aluminium alloys highly depend on temperature and vital properties degradation occurs at elevated temperatures. The response of aluminium alloy becomes increasingly nonlinear at elevated temperatures.

A great number of experimental and numerical investigations on aluminium alloy beams at ambient temperatures have been carried out, including Lai and Nethercot [6], Moen et al. [7,8], Zhu and Young [9], and Su et al. [10]. As for the aluminium alloy structural members at elevated temperature, the majority studies are focused on columns [11-13]. Studies on aluminium alloy beams at high temperatures are limited. Meulen [14] performed the steady state and transient state experiments on 6060-T66 aluminium alloy beams of square hollow sections. Steady state tests were carried out between the range of $250^{\circ} \mathrm{C}$ to $300^{\circ} \mathrm{C}$; transient state tests were conducted at a rate of either $2.5^{\circ} \mathrm{C} / \mathrm{min}$ or $10^{\circ} \mathrm{C} / \mathrm{min}$. From steady state test results, it was found that the cross-sectional classification limits in Eurocode 9 (EC9) $[15,16]$ are applicable for specimens at temperatures smaller than $250^{\circ} \mathrm{C}$, while EC9 also agrees well with transient state test results if specimens were heated less than 120 mins. Suzuki et al. [17] performed experiments on aluminium alloy (5083H112) $\mathrm{H}$-section beams to investigate the flexural performance at fire and critical temperature. The critical temperatures predicted by EC9 $[15,16]$ were found to be conservative. Zheng and Zhang [18] developed numerical models for aluminium alloy I-section beams and validated against experimental results on aluminium alloy 5083-H112 conducted by Suzuki et al. [17] and aluminium alloy 6060-T66 by Maljaars et al. [12].

The development and application of aluminium alloys have been supported by existing international design rules, such as the American Aluminum Design Manual (ADM) [19], the Australian/New Zealand Standard (AS/NZS) [20] and Eurocode 9 (EC9) [15]. The thermal 
properties including thermal expansion and reduction factors are included in Appendix 4, Part I of ADM [19] and Part 1-2 of EC9 [16]. Substituting the reduced material properties into design equations in ADM, AS/NZS, EC9 and CSM, the strengths of aluminium alloy structural members at elevated temperatures could be obtained. Gardner [21], Gardner and Ashraf [22] and Su et al. [23] proposed a deformation - based design approach, the continuous strength method (CSM) for aluminium alloy members. The result comparison revealed that the CSM can increase the accuracy and consistency of the prediction by adopting the new base curve showing the continuous relationship between cross-section deformation capacity and slenderness. The appropriateness of the CSM approach for aluminium alloy members at elevated temperatures can also be assessed by adopting the material properties at corresponding temperatures.

The present paper aims to investigate the flexural behaviour and design of aluminium alloy beams at elevated temperatures. The aluminium alloy beam tests [14] and tensile coupon tests [24] conducted at elevated temperatures were collected from literature. A numerical model of aluminium alloy beams on square hollow sections was developed using ABAQUS programme [25] and validated against experimental results [14]. The validated finite element (FE) model was used to conduct parametric study based on the tensile coupon test results of normal and high strength aluminium alloys [24]. A total of additional 120 numerical results of aluminium alloy beams at elevated temperatures were generated from parametric study. Both the collected experimental results and newly generated numerical data were utilised to assess the existing design equations in the ADM, the AS/NZS, EC9 and the CSM. Reliability analysis was also performed to assess the reliability and safety of existing design rules.

\section{Data collection}

The data at elevated temperatures collected and used in this paper are three-point bending tests performed by Meulen [14] and tensile coupon tests conducted by Su and Young [24].

\subsection{Three-point bending test results}

A total of eight three-point bending tests on aluminium alloy beams at high temperature were conducted by Meulen [14]. The beams were extruded by aluminium alloys 6060-T66. The cross- 
sections of the beams were square hollow sections with nominal outer dimension of $100 \mathrm{~mm}$ and nominal thickness of $3 \mathrm{~mm}, 4 \mathrm{~mm}$ or $5 \mathrm{~mm}$. Two lengths of $1000 \mathrm{~mm}$ and $2000 \mathrm{~mm}$ were considered. Table 1 summarized the cross-section diameters, material properties obtained at corresponding temperatures and the loading capacities. The symbols presented in Table 1 are defined as follow: $B$ and $H$ are the outer dimension, $t$ is the thickness, $L$ is the beam length, $D$ is the length of the supporting insulation at middle of span, $E$ is the Young's modulus, $f_{\mathrm{y}}$ is the yield stress, which is taken as $0.2 \%$ proof stress, $f_{u}$ is the ultimate stress, $T$ is the temperature at which the test was conducted and $P_{\exp }$ is the experimental ultimate force, which is taken as the maximum force that the specimen can endure. The experiments were conducted by steady state method at $250 \square$ and $300 \square$. Details of the test setup can be referred to Ref. [14]. The results summarized in Table 1 are used to validate the newly developed finite element model in this study as detailed in Section 3.1 of this paper.

\subsection{Tensile coupon test results}

Su and Young [24] reported material properties of normal strength aluminium alloy 6063-T5 and high strength aluminium alloy 6061-T6 at elevated temperatures ranging from 24 to $600^{\circ} \mathrm{C}$. Both static state tests and transient state tests were performed by Su and Young [24], but only results from steady state tests are collected and used herein. In steady state tests, specimens were loaded to failure at a constant temperature, while in the transient state tests, specimens were heated up to failure at a specified load level. In steady state tests, the specimens were heated up under 10 various nominal temperatures ranging from $24^{\circ} \mathrm{C}$ to $600^{\circ} \mathrm{C}$ with intervals of $50^{\circ} \mathrm{C}$ or $100^{\circ} \mathrm{C}$. The upper end of specimen was fixed while the lower end was free for expansion during the process of heating until it reaches to the required temperature. After the required temperature was stabilized for ten minutes, the lower end of specimen was gripped. The load to the specimens was given through displacement with a constant loading rate of $0.3 \mathrm{~mm} / \mathrm{min}$ until failure. Key material properties at elevated temperatures reported by Su and Young [24] are summarized in Table 2 and used to conduct the parametric study as detailed in Section 3.2 of this paper.

\section{Numerical study}

Finite element (FE) model for three-point bending beams was developed using ABAQUS 
programme [25]. The model was validated against the experimental results [14]. Upon validation, the FE model was employed for parametric study using material properties reported by $\mathrm{Su}$ and Young [24].

\subsection{Model validation}

The full length and full cross-section of the beam specimens were built in the FE model. The model was built based on centreline dimensions of cross-sections. The reduced integration 4-node general-purpose shell (S4R) element that has six degrees of freedom per node was used in numerical studies. The S4R element with a uniform mesh size of $10 \mathrm{~mm} \times 10 \mathrm{~mm}$ for all numerical specimens and solid plates provide accurate solutions with reasonable computational time. A $10 \mathrm{~mm}$ thick solid plate that rotated in-plane freely was used to simulate the bearing plate, since the rotation of the steel bearing plate in the tests was not fixed and it might have in-plane rotation due to the beam deformation. In modelling, the contact employed between the bottom surfaces of solid plate (master surface) and the top surfaces of beam (slave surface) is hard contact in the normal direction and friction penalty contact (with the friction coefficient $=0.15$ ) in the tangential direction. The interface between the steel bearing plate and the aluminium alloy beam was mainly subjected to friction in tests, since the plate was not tied or fixed to the beam. This friction coefficient depends on the materials not the loading level. Penetration of the two contact surfaces was avoided. Modelling of boundary conditions was applied in accordance with the experimental conditions. Reasonable degrees of freedom at the mid-span and at the bottom flange of the beams were restrained to simulate boundary conditions. The beams were restrained longitudinally at the mid-span only. It is found in literature that Riks programme in ABAQUS can capture post-ultimate path of loading specimens [25]. In this study, the Riks programme was used to apply loads on specimens by displacement-control [25], which is identical to the experimental condition. The type and size of meshes and boundary conditions have been found to provide accurate solutions for aluminium alloy beams at room temperature [10].

The material properties used in the modelling includes elastic part (linear) and strain hardening part (nonlinear). Linear region is determined by the Young's modulus, the yield stress and the Poisson's ratio. The nonlinear part is determined by plastic behaviour through approximately 20 
sets of corresponding true stress $\sigma_{\text {true }}$ and plastic strain $\varepsilon_{\text {true }}^{p l}$. The true stress and plastic true strain can be calculated according to Eqs (1) and (2) based on engineering stress $\sigma$ and engineering strain $\varepsilon$, respectively. Residual stresses in the test specimens were not measured and not explicitly modelled in the FE analysis due to the reasons explained in Su et al. [26].

$\sigma_{\text {true }}=\sigma(1+\varepsilon)$

$\varepsilon_{\text {true }}^{p l}=\ln (1+\varepsilon)-\sigma_{\text {true }} / E$

The newly developed FE model was validated by comparing the ultimate loads, the loaddeformation capacities and the failure modes with the tested specimens. The comparison of typical failure modes from experiments and numerical simulation is shown in Fig. 1. The ultimate forces obtained from the numerical analyses $\left(P_{F E M}\right)$ and experiments $\left(P_{\exp }\right)[14]$ were compared in Table 3. The numerical results agree well with experimental results, which is approximately $5 \%$ overprediction with a small scatter $(\mathrm{CoV}=0.053)$. Comparisons for full load-displacement curves of the two specimens from experiment [14] and finite element predictions are depicted in Fig. 2. In general, the comparison proves that the newly developed finite element model was able to predict the structural response of the three-point bending beams at elevated temperatures accurately. However, some difference of the load paths between FE model predictions and test results could also be observed, which is believed to be caused by the following two reasons. First, the material properties incorporated in the FE model was obtained from tensile coupon tests at elevated temperature. However, the temperature of beam specimens at elevated temperatures in the actual tests might not be uniform. In addition, the steel bearing plate might have movement or rotation against the beam, since it was just placed on the surface of the beam without mechanical anchorage. It might be the reason for the inconstant stiffness of the numerical curve.

\subsection{Parametric study}

The validated numerical model was employed for the parametric study to assess the influences of key parameters (cross-section slenderness, temperature and material strength) on the behaviour of aluminium alloy beams. Both normal strength aluminium alloy 6063-T5 and high strength aluminium alloy 6061-T6 were considered in the parametric study. The material properties at elevated temperatures were obtained from tensile coupon tests conducted by Su and Young [24]. A 
total of 120 specimens of square hollow section with the cross-sectional dimension of $100 \mathrm{~mm} \times$ $100 \mathrm{~mm}$ and length of $2000 \mathrm{~mm}$ were generated. The numerical models covered a wide range of the $b / t$ ratios of cross-sections (from 8 to 38). Numerical analyses were performed at ten elevated temperatures ranging from $24^{\circ} \mathrm{C}$ to $600^{\circ} \mathrm{C}$ with intervals of $50^{\circ} \mathrm{C}$ or $100^{\circ} \mathrm{C}$.

The numerical specimens designed in the parametric study are labelled in accordance to the material strength, cross-sectional dimensions and temperature. For example, the label "H100×100×5-T300" has the following definitions:

- The first letter means the type of material. In this label, the specimen is of high strength aluminium alloy 6061-T6. If a label starts with the letter "N", it indicates the specimen is of normal strength aluminium alloy 6063-T5.

- The second part of label shows the cross-sectional dimensions as width $\times$ height $\times$ thickness ( $\mathrm{mm}$ in unit).

- The last part of the label "T300" indicates the temperature at which the test/simulation was conducted.

The ultimate bending moments at elevated temperatures from the parametric studies $M_{F E M}$ are presented in Fig.3(a) and (b) for aluminium alloy 6061-T6 and aluminium alloy 6063-T5, respectively. It can be seen from the Fig. 3 that significant decrease of flexural capacities can be observed from $300^{\circ} \mathrm{C}$ to $600^{\circ} \mathrm{C}$ for aluminium alloy $6061-\mathrm{T} 6$ beams, while for aluminium alloy 6063-T5 beams, the reduction in flexural resistance is generally consistent from $100^{\circ} \mathrm{C}$ to $600^{\circ} \mathrm{C}$.

\section{Design methods and result comparisons}

This section compares the ultimate bending capacities obtained from experimental $\left(M_{\text {exp }}\right)$ and finite element modelling $\left(M_{F E M}\right)$ with design rule predictions. The design strengths are predicted by existing rules of the Aluminum Design Manual [19] $\left(M_{A D M}\right)$, the Australian/New Zealand Standard [20] $\left(M_{A S / N Z S}\right)$, Eurocode 9 [15] $\left(M_{E C 9}\right)$ and the continuous strength method [23] $\left(M_{c s m}\right)$ using the reduced material properties at elevated temperatures. All partial safety factors were set equal to unity in the calculation. 


\subsection{Aluminum Design Manual}

The design rules of Aluminum Design Manual (ADM) [19] for aluminium alloy simply supported beams are in Clause F.3.1, in which weighted average method is used. The design moment capacity determined by weighted average method is the sum of elastic section modulus of flange and web multiplied by their local buckling stress of flange and web, respectively. The material properties used for calculation are taken as measured room temperature properties multiplied by reduction factors codified in $\mathrm{ADM}$ for $M_{A D M-1}$ and measured material properties at elevated temperatures for $M_{A D M-2}$.

\subsection{Australian/New Zealand Standard}

The design rules in the Australian/New Zealand Standard (AS/NZS) [20] are similar to that in the ADM [19]. Clause 4.7.2 in the AS/NZS [20] claims that the limit state compressive stress for the beam section takes the weighted average of the limit state stress of compression flange and webs. The vital difference between ADM and AS/NZS is the approach to determine the cross-sectional design stress, where area is adopted in the AS/NZS while modulus of the cross-section is opted in ADM. The material properties used for calculation are measured at elevated temperatures.

\subsection{Eurocode 9}

In terms of Eurocode 9 (EC9) [15], design rules for bending moment capacity are in Clause 6.2.5. The first step of calculation is to classify the cross-section, which is described in Clause 6.1.4.4. Then, moment capacity of cross-section for each class can be determined. For Classes 1 and 2 sections, moment capacity is defined as yield stress $f_{y}$ multiplied by the plastic section modulus $W_{p l}$. For Class 3 sections, it is determined by using yield stress $f_{y}$ multiplied by elastic section modulus $W_{e l}$. With regards to Class 4 sections, moment capacity is determined as elastic section modulus of an effective section $W_{\text {eff }}$ multiplied by yield stress $f_{y}$. The material properties used are measured room temperature properties multiplied by reduction factors codified in EC9 for $M_{\mathrm{EC} 9-1}$ and measured material properties at elevated temperatures for $M_{E C 9-2}$.

\subsection{Continuous strength method}

The continuous strength method (CSM) [23] is a deformation-based design approach. In terms of 
CSM of aluminium alloys, base curve and bi-linear material model are two significant features. The base curve defines the limiting level of strain $\varepsilon_{c s m}$ that the cross-section can withstand before it fails. In the CSM, the continuous relationship between cross-sectional deformation capacity and slenderness is presented by the base curve [23]. The cross-sectional slenderness $\overline{\lambda_{p}}$ is defined in a dimensionless form as the square root of the ratio of the yield stress to the cross-sectional elastic buckling stress. The elastic buckling stress $\sigma_{c r}$ can be calculated by simplified equations [27] or numerical programs such as CUFSM [28]. Theofanous et al. [29] extended the CSM for steel cross-section design at elevated temperatures by considering the temperature effects on the base curve and material stress-strain model. In accordance with the CSM for steel cross-sections at elevated temperature [29], the CSM $\left(M_{c s m}\right)$ for aluminium alloys at room temperature [23] is extended herein to the structural fire design of aluminium alloy beams by adopting the material properties measured at elevated temperatures.

\subsection{Comparison of results}

A total of 128 numerical and experimental results are utilised for comparison. The results are summarised in Tables 4 - 7, as well as Figs. 4 - 5. In general, the design strengths determined by the six design methods considered in this study are conservative. The predictions of ADM and EC9 using the codified material properties are significantly conservative and hugely scatter, which are due to the inaccurate prediction of material properties. When substituting the measured material properties into the design rules of ADM and EC9, the predictions display improved accuracy and consistency of predictions: the mean values of $M_{F E M} / M_{A D M-2}, M_{F E M} / M_{E C 9-2}$ ratios are 1.16 and 1.20 with the corresponding CoVs of 0.158 and 0.139 . The determination of accurate temperature dependant material parameters is shown to be crucial for the successful application of design methods. The AS/NZS design rules using the measured material properties appears to be rather conservative, which has the mean value of $M_{F E M} / M_{A S / N Z S}$ of 1.34 and with a coefficient of variation $(\mathrm{CoV})$ being 0.250 . In comparison with other design methods, the CSM approach yields the most accurate prediction with the least scatter (mean value $=1.16$ and the $\mathrm{CoV}=0.121$ ) although it is slightly conservative. Therefore, at the elevated temperature condition, the CSM approach is also found to appropriate for the aluminium alloy flexural design. Its advantages 
compared to other existing design rules have been demonstrated not only for the aluminium alloy structural design at room temperature [23], but also at high temperatures in this study.

The influence of slenderness ratio $b / t$ and temperature on the behaviour of aluminium alloy beams subjected at high temperatures are investigated herein. For effect of slenderness, the results show that the trends of numerical-to-predicted moment capacity ratios are similar at different temperature conditions (see Fig. 4). The trend of predicted results indicate that the design methods are more accurate when predicting the flexural strength of slender sections $(b / t>20)$. The degree of conservatism of design predictions increases with the decreasing slenderness (i.e. stockier sections), whilst the conservatism is less pronounced in the CSM predictions. Similar results were also reported by Theofanous et al. [29] for steel members. The reason might be attributed to the neglect of strain hardening characteristics of aluminium alloys by existing design methods, which has more pronounced effects on the stocky sections. It can be seen that in all cases, the CSM approach generally provides the most accurate results for non-slender sections. In terms of effect of temperature on prediction, Fig. 5 shows that there is no significant difference at different temperatures for the same cross-section slenderness. The CSM generally offers improved accuracy compared to other design methods for all temperature range owing to the consideration of interaction between adjacent elements in a cross-section [23].

\section{Reliability analyses}

In this study, reliability index $\beta$ is employed to evaluate the reliability level of design rules. The target reliability index $\beta_{o}$ of 2.50 for beam is specified in the ADM [19], which means that if the calculated $\beta$ is greater than or equal to 2.50 , the design rule can be deemed as reliable and safe. The load combinations between Dead Loads (DL) and Live Loads (LL) are used for analysis. A load combination of $1.2 \mathrm{DL}+1.6 \mathrm{LL}$ is adopted for the ADM [19] and CSM [23], 1.25DL + 1.50LL for the AS/NZS [20] and 1.35DL + 1.50LL for EC9 [15]. Resistance factor $\varphi$ is taken as 0.90 for ADM and CSM, 0.85 for AS/NZS and 0.91 for EC9. The input parameters used in the calculation are codified in the Clause 1.3.2 of Appendix 1, Part I of ADM [19]. The material overstrength factor $M_{m}$ equals to 1.10 if the member behaviour is governed by $f_{y}$ while $M_{m}$ equals to 1.00 if the behaviour is governed by $f_{u}$. The calculation method of $M_{m}$ for different design methods 
are explained in detail by Su et al. [23]. In addition, the values of other parameters are as follow: $F_{m}=1.00, V_{M}=0.06, V_{F}=0.05$, and $V_{Q}=0.21$. Table 7 presented the calculated reliability index $\beta$ for the six design methods. It is found that all calculated reliability indexes of design rules using measured material properties are greater than the target reliability index of 2.50 , which indicates that the four design rules are reliable in terms of flexural design for aluminium alloy beams at elevated temperatures.

\section{Conclusions}

A numerical model was developed and validated against the test results of simply supported beams [14]. Upon validation, the finite element model was used to generate a total of additional 120 numerical results based on the material properties of aluminium alloys at elevated temperatures [24]. The numerical specimens covered a wide range of cross-section width-tothickness ratio from 8 to 38 and ten different temperatures from $24 \square$ to $600 \square$. A total of 128 numerical and experimental results were utilised for comparisons of the experimental and numerical results with the design strengths of the ADM, the AS/NZS, EC9 and the CSM. In general, the design strengths predicted by these design methods were conservative. Among the four design methods, the AS/NZS was found to be the most conservative while the accuracy and consistency of the CSM was verified. The calculated reliability indices show that all design guidelines using the measured material properties are reliable for the prediction of flexural capacities of aluminium alloy beams at elevated temperatures.

\section{Acknowledgements}

The authors are thankful to Dr. Meulen for providing the detail information of three-point bending tests at high temperatures. We would like to thank the funding support from the Chinese National Natural Science Foundation (51538007, 51890902, 51778085).

\section{Notations}

$\begin{array}{ll}B & \text { Width of flange } \\ b & \text { Flat width of flange } \\ \mathrm{CoV} & \text { Coefficient of variation }\end{array}$




\begin{tabular}{|c|c|}
\hline$D$ & Length of the supporting insulation at mid \\
\hline$E$ & Young's modulus \\
\hline$E_{s h}$ & Strain hardening modulus \\
\hline$F_{\exp }$ & Experimental ultimate load of simply supported beams \\
\hline$F_{F E M}$ & Numerical ultimate load of simply supported beams \\
\hline$F_{m}$ & Mean values of fabrication factor \\
\hline$f_{u}$ & Ultimate stress \\
\hline$f_{y}$ & Yield stress, taken as the $0.2 \%$ proof stress \\
\hline$H$ & Width of web \\
\hline$h$ & Flat width of web \\
\hline$L$ & Length of the beam \\
\hline$M_{A D M}$ & Moment capacity predicted by the ADM [14] \\
\hline$M_{A S / N Z S}$ & Moment capacity predicted by the AS/NZS [15] \\
\hline$M_{c s m}$ & Moment capacity predicted by the CSM \\
\hline$M_{E C 9}$ & Moment capacity predicted by EC9 [10] \\
\hline$M_{e l}$ & $W_{e l f}$ is the elastic moment capacity \\
\hline$M_{\text {exp }}$ & Moment capacities obtained from three-point bending tests \\
\hline$M_{F E M}$ & Moment capacities obtained from finite element modelling \\
\hline$M_{m}$ & Mean values of material properties factor \\
\hline$M_{p l}$ & $W_{p} f_{y}$ is the plastic moment capacity \\
\hline$M_{u}$ & Experimental or numerical moment capacities \\
\hline$P_{m}$ & Mean value of test and numerical-to-predicted moment capacities ratios \\
\hline$t$ & Wall thickness \\
\hline$V_{F}$ & Coefficients of variation of fabrication factor \\
\hline$V_{M}$ & Coefficients of variation of material properties factor \\
\hline$V_{P}$ & Coefficient of variation of test and numerical-to-predicted load ratios \\
\hline$V_{Q}$ & Coefficient of variation of load effect \\
\hline$W_{\text {eff }}$ & Elastic modulus of effective section \\
\hline$W_{e l}$ & Elastic section modulus \\
\hline$W_{p l}$ & Plastic section modulus \\
\hline$x$ & Proportion of ultimate strain \\
\hline$\beta$ & Reliability index \\
\hline
\end{tabular}




$\begin{array}{ll}\beta_{o} & \text { Target reliability index } \\ \varepsilon & \text { Engineering strain } \\ \varepsilon_{c s m} & \text { CSM limiting strain } \\ \varepsilon_{\text {true }}^{p l} & \text { True plastic strain } \\ \varepsilon_{u} & \text { Strain at ultimate tensile stress } \\ \varepsilon_{y} & \text { Yield strain }\left(f_{y} / E\right) \\ \phi & \text { Resistance factor } \\ \overline{\lambda_{p}} & \text { Cross-sectional slenderness } \\ \sigma & \text { Engineering stress } \\ \sigma_{c r} & \text { Elastic buckling stress } \\ \sigma_{\text {true }} & \text { True stress }\end{array}$

\section{References}

[1] Höglund T. (1997) "Shear buckling resistance of steel and aluminium plate girders", Thin-Walled Structures, 29 (1-4): 13-30.

[2] Shi Y. J., Wang Y.Q., Cheng M., Yuan H.X. (2010), “Analysis of shear strength of thin plate aluminum girders" Gongcheng Lixue/Engineering Mechanics, 27 (9): 69-73.

[3] Brando G., De Matteis G. (2011), "Experimental and numerical analysis of a multistiffened pure aluminium shear panel", Thin-Walled Structures, 49 (10): 1277-1287.

[4] Brando G., De Matteis G. (2014), "Design of low strength-high hardening metal multistiffened shear plates" Engineering Structures, 60: 2-10.

[5] Su, M., Young, B. and Gardner, L. (2016), "Flexural resistance of aluminium alloy SHS/RHS with internal stiffeners", Engineering Structures, 121: 170-180.

[6] Lai YFW, Nethercot DA. Strength of aluminium members containing local transverse welds. Eng Struct 1992;14(4):241-54.

[7] Moen LA, Hopperstad OS, Langseth M. Rotational capacity of aluminium beams under moment gradient. I: experiments. J Struct Eng, ASCE 1999;125(8):910-20.

[8] Moen LA, De Matteis G, Hopperstad OS, Langseth M, Landolfo R, Mazzolani FM. Rotational capacity of aluminium beams under moment gradient. II: numerical simulations. J Struct Eng ASCE 1999;125(8):921-9.

[9] Zhu JH, Young B. Design of aluminum alloy flexural members using direct strength method. J Struct Eng, ASCE 2009;135(5):558-66.

[10] Su M, Young B, Gardner L. Deformation-based design of aluminium alloy beams. Eng Struct 2014; 80:339-49.

[11] Maljaars J, Soetens F, Snijder H.H. Local buckling of aluminium structures exposed to fire. Part 1: Tests. Thin-Walled Struct. 2009, 47(11), 1404-1417.

[12] Maljaars J, Soetens F, Snijder H.H. Local buckling of aluminium structures exposed to fire. Part 2: Finite element models. Thin-Walled Struct. 2009, 47(11), 1418-1428.

[13] Langhelle N.K., Amdahl J. Experimental and Numerical Analysis of Aluminium 
Columns Subjected to Fire. In Proc. Eleventh International Offshore and Polar Engineering Conference, Stavanger, Norway, 17-22 June, 2001. p. 406-413.

[14] Meulen O.R. Local buckling of aluminium beams in fire conditions, Doctor of Philosophy, Department of Built Environment, Eindhoven; 2015. $<$ https://research.tue.nl/en/publications/local-buckling-of-aluminium-beams-in-fireconditions $>$

[15] European Committee for Standardization (EC9). Eurocode 9: design of aluminium structures-Part 1-1: general structural rules. BS EN 1999-1-1:2007, CEN; 2007.

[16] European Committee for Standardization (EC9). Eurocode 9: design of aluminium structures-Part 1-2: structural fire design. BS EN 1999-1-2:2007, CEN; 2007.

[17] Suzuki J, Ohmiya Y, Wakamatsu T, Harada K, Yusa S, Kohno M. Evaluation of Fire Resistance of Aluminum Alloy Members. Fire Science and Technology. 2005;24(4):237-255.

[18] Zheng YQ, Zhang Z. The fire performance and fire-resistance design of aluminium alloy I-beams. Fire and Material. 2016, 40:141-157.

[19] Aluminum Association. Aluminum design manual. Washington, DC; 2015.

[20] Australian/New Zealand Standard (AS/NZS). Aluminum structures part 1: limit state design. AS/NZS 1664.1:1997, Standards Australia, Sydney, Australia; 1997.

[21] Gardner L. The continuous strength method. Proceedings of the Institution of Civil Engineers - Structures and Buildings. 2008;161(3):127-133.

[22] Gardner L, Ashraf M. Structural design for non-linear metallic materials. Eng Struct. 2006;28(6):926-934.

[23] Su M, Young B, Gardner L. The continuous strength method for the design of aluminium alloy structural elements. Eng Struct. 2016; 122:338-348.

[24] Su, M. N., Young B., "Material Properties of Normal and High Strength Aluminium Alloys at Elevated Temperatures". Thin-walled Structures, in press.

[25] ABAQUS analysis user's manual, version 2016. Simulia (Dassault Systèmes); 2015.

[26] Su, M., Young, B. and Gardner, L. (2015), "Continuous beams of aluminum alloy tubular cross sections. I: tests and model validation”, Journal of Structural Engineering, ASCE, 141(9): 04014232.

[27] Seif M, Schafer BW. Local buckling of structural steel shapes. J Constr Steel Res 2010;66(10):1232-47.

[28] Li Z, Schafer BW. Buckling analysis of cold-formed steel members with general boundary conditions using CUFSM: conventional and constrained finite strip methods. In: Proceedings of the 20th international specialty conference on cold-formed steel structures. St. Louis, USA; 2010. p. 17-31.

[29] Theofanous, M. Propsert, T., Knobloch, M., Gardner, L., The continuous strength method for steel cross-section design at elevated temperatures, Thin-Walled Structures, 2016, 98:94102. 


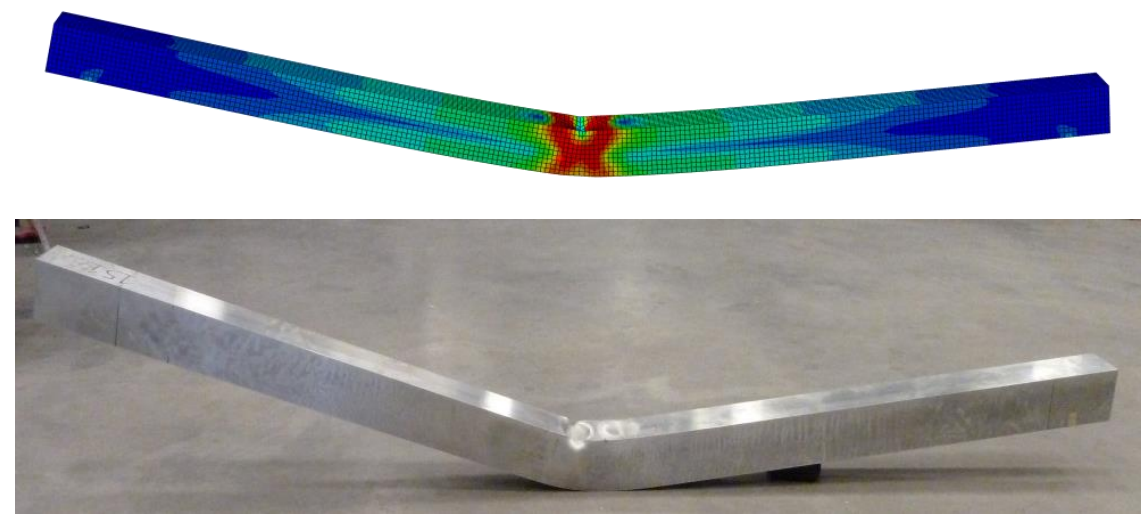

Fig. 1. Typical failure modes of finite element model and test specimen (specimen 151A [14]) 


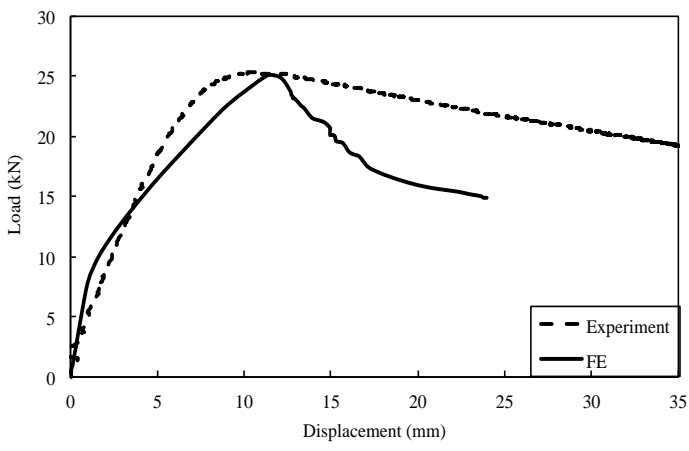

(a) Specimen subjected to $250^{\circ} \mathrm{C}(154 \mathrm{~A})$

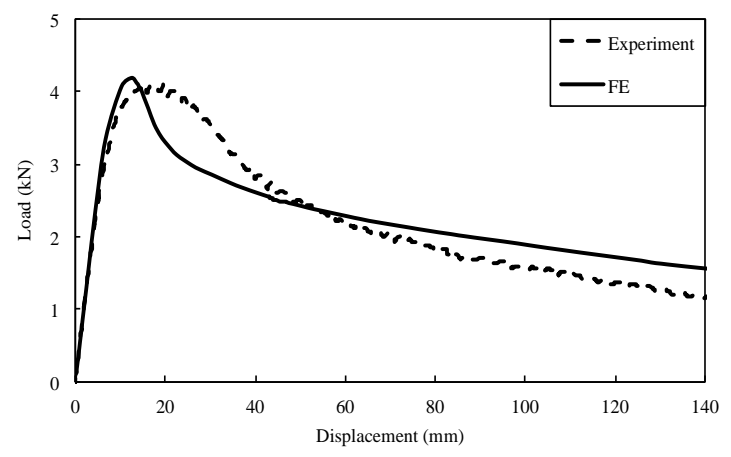

(b) Specimen subjected to $300^{\circ} \mathrm{C}(133 \mathrm{~A})$

Fig. 2. Comparisons between experimental [14] and numerical load-deformation curves 


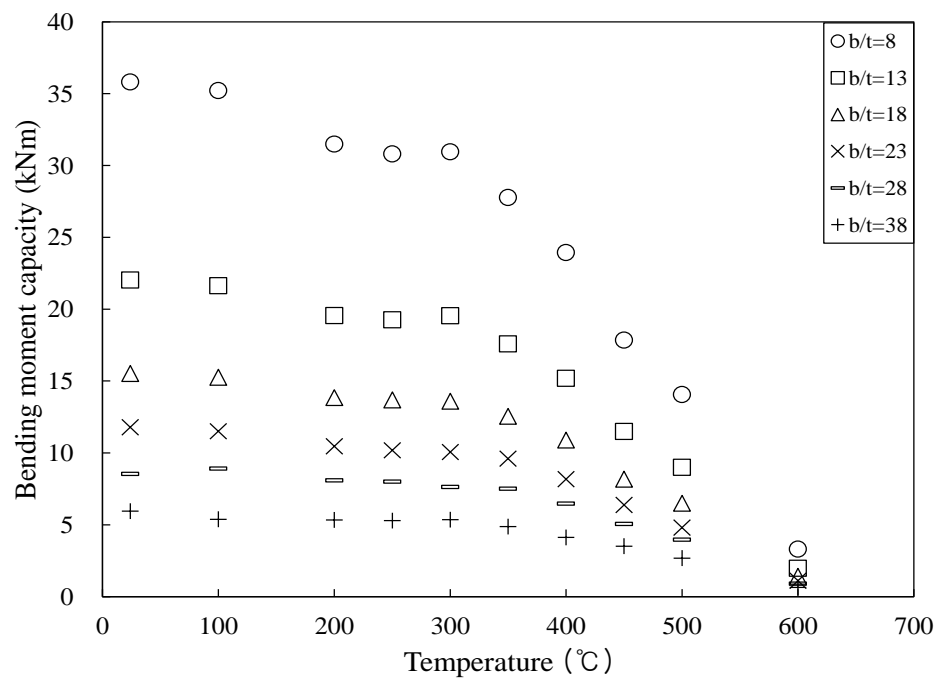

(a) Alloy 6061-T6

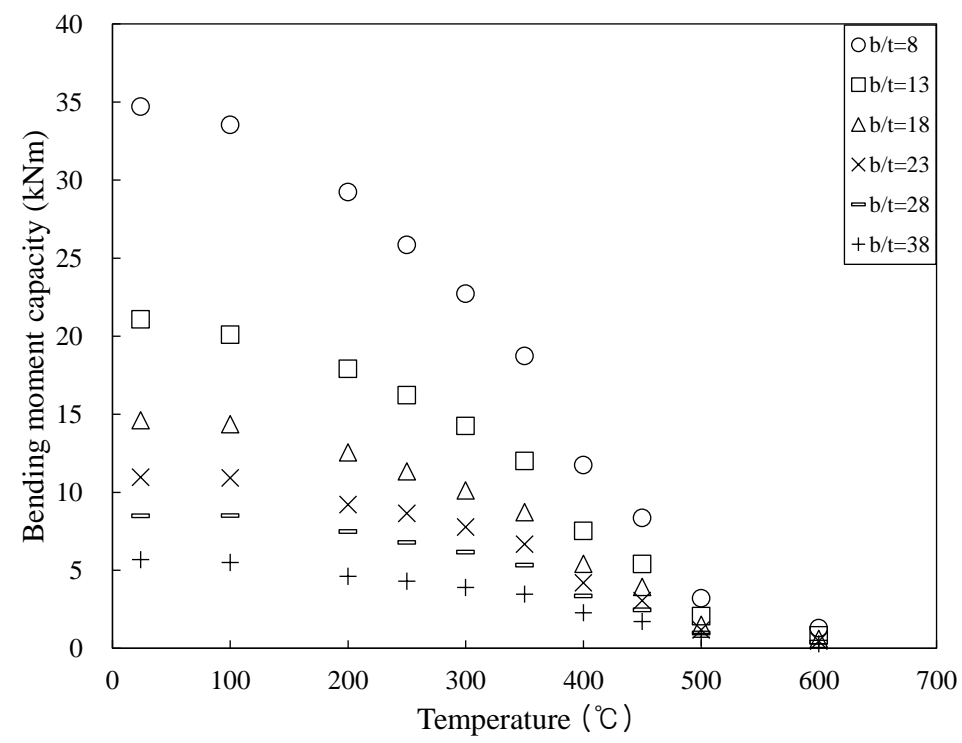

(b) Alloy 6063-T5

Fig. 3. Bending moment capacities of FE models at elevated temperatures 


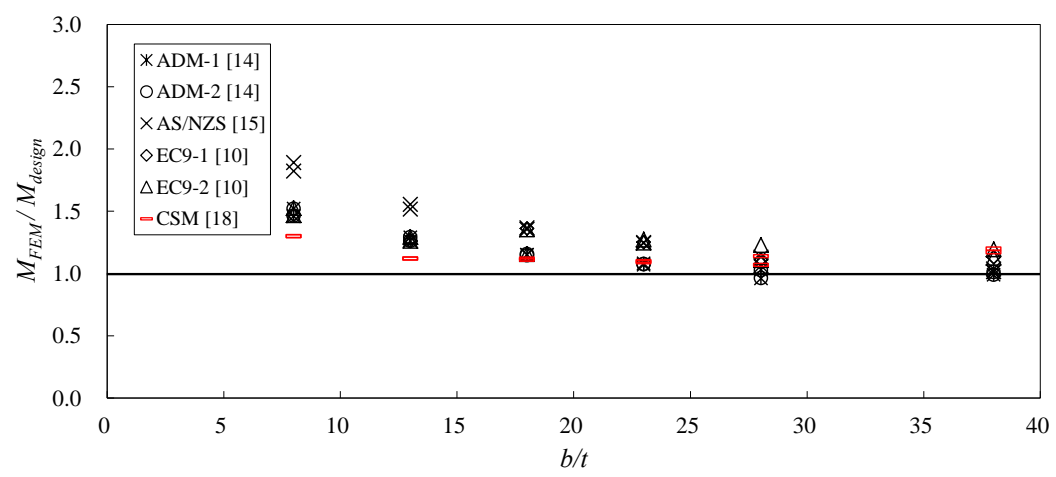

(a) $24^{\circ} \mathrm{C}$

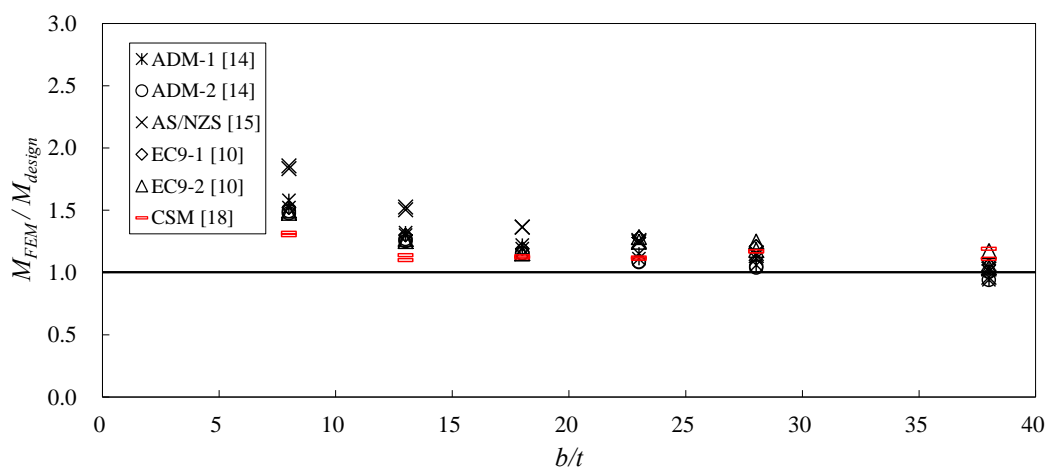

(b) $100^{\circ} \mathrm{C}$

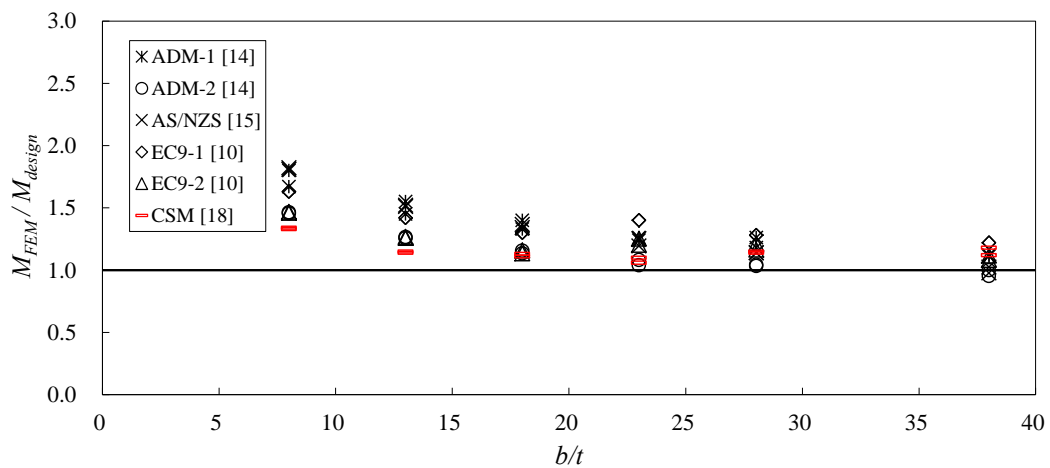

(c) $200^{\circ} \mathrm{C}$

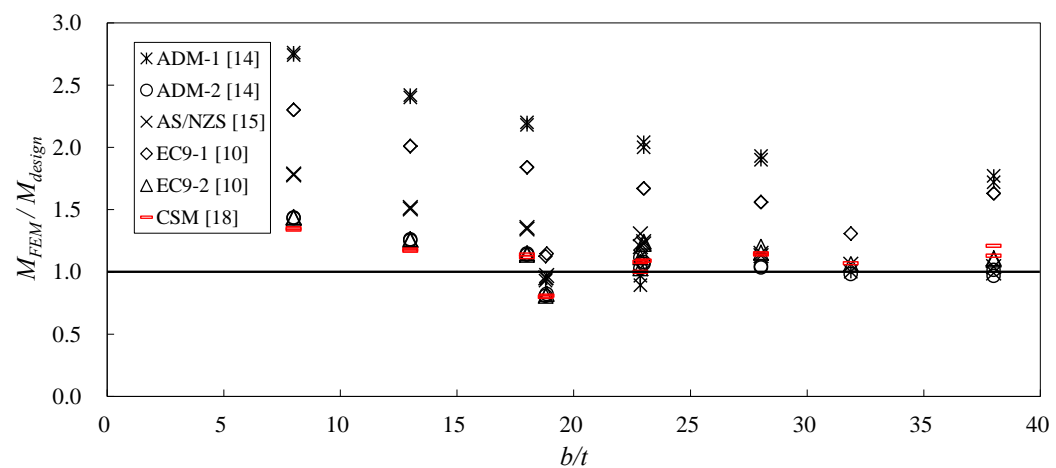

(d) $250^{\circ} \mathrm{C}$ 


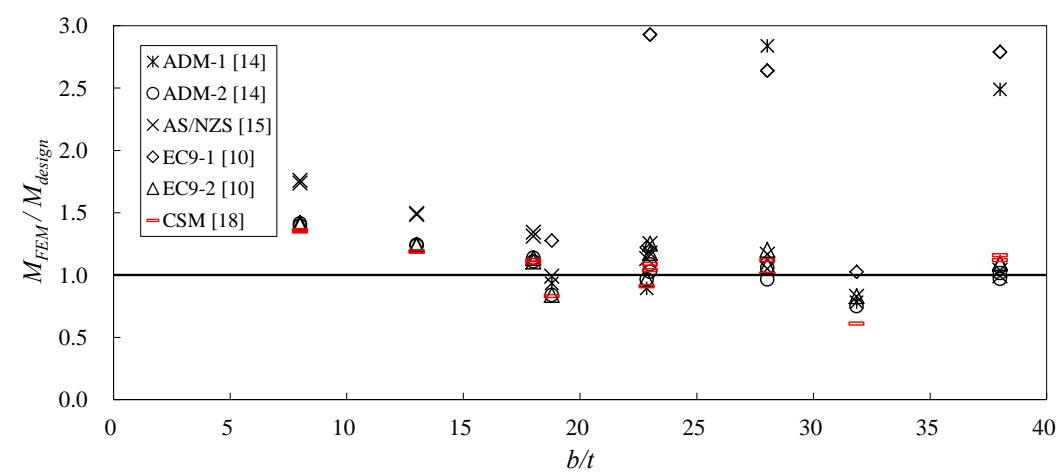

(e) $300^{\circ} \mathrm{C}$

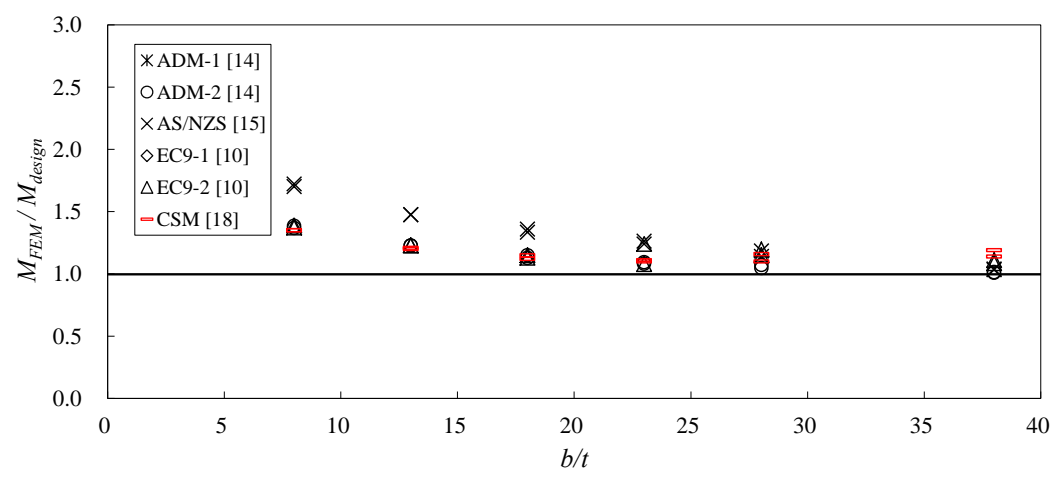

(f) $350^{\circ} \mathrm{C}$

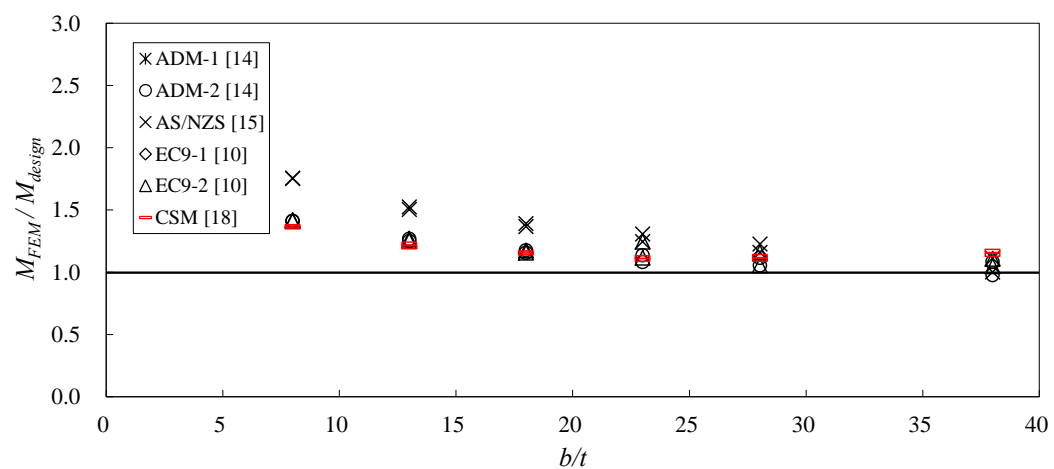

(g) $400^{\circ} \mathrm{C}$

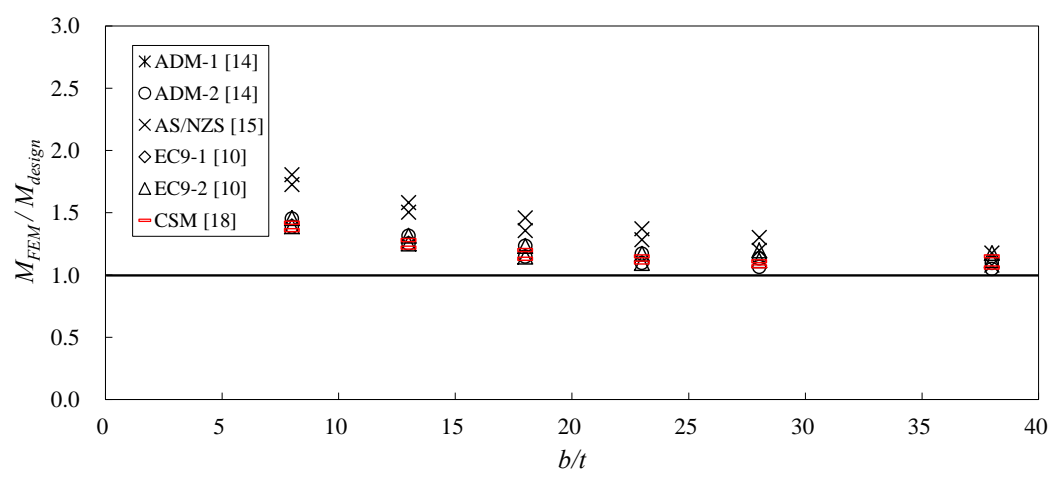

(h) $450^{\circ} \mathrm{C}$ 


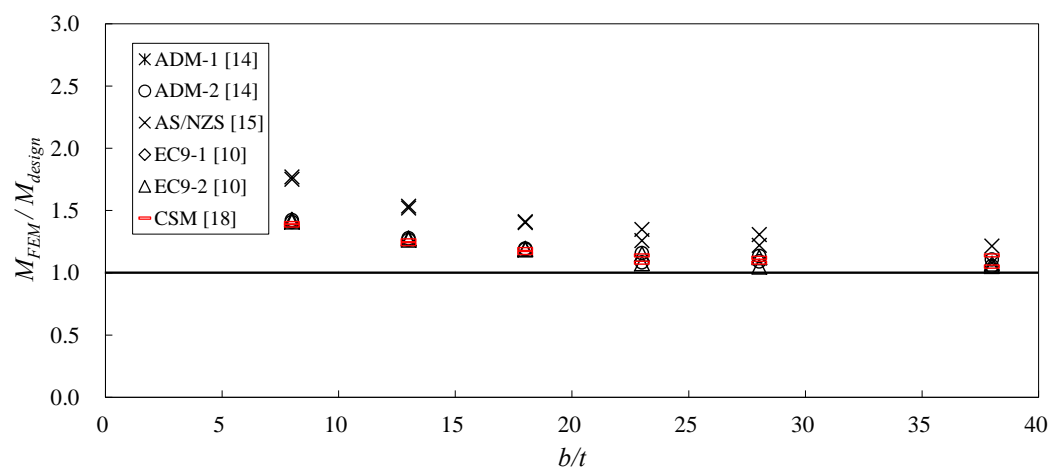

(i) $500^{\circ} \mathrm{C}$

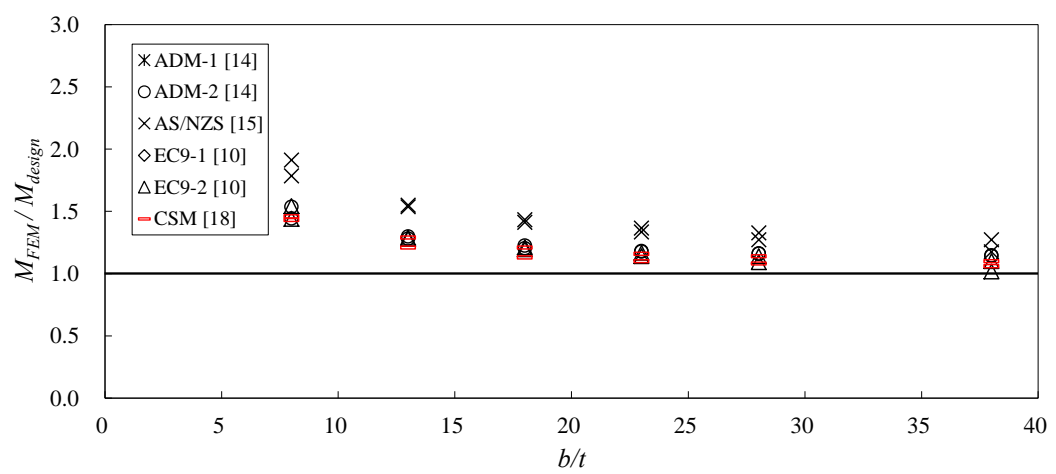

(j) $600^{\circ} \mathrm{C}$

Fig. 4. Comparison of numerical and experimental results with design strengths against $b / t$ ratio 


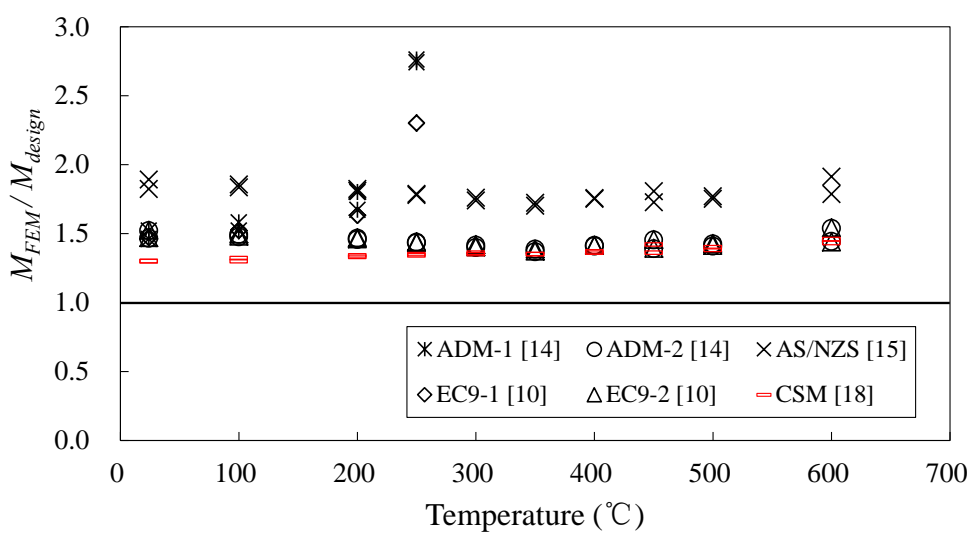

(a) $b / t=8$

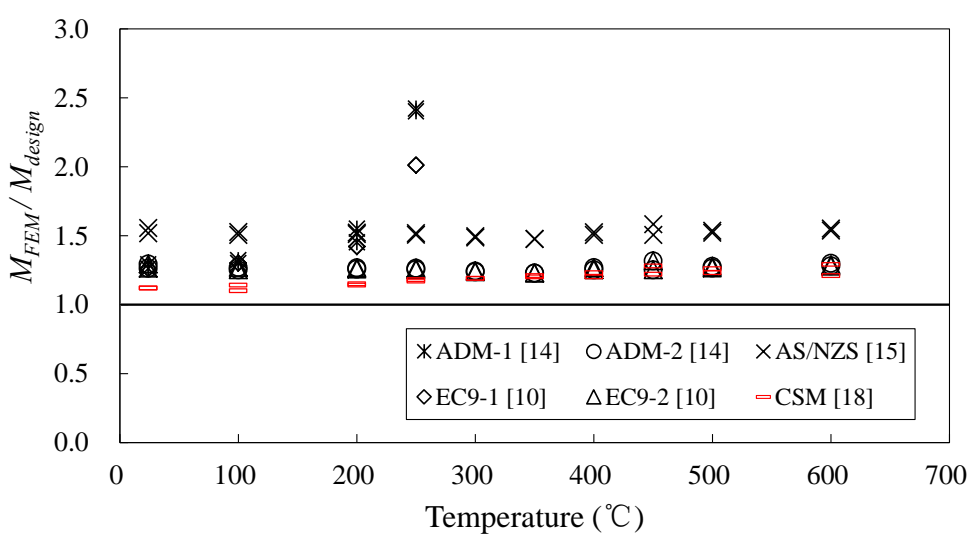

(b) $b / t=13$

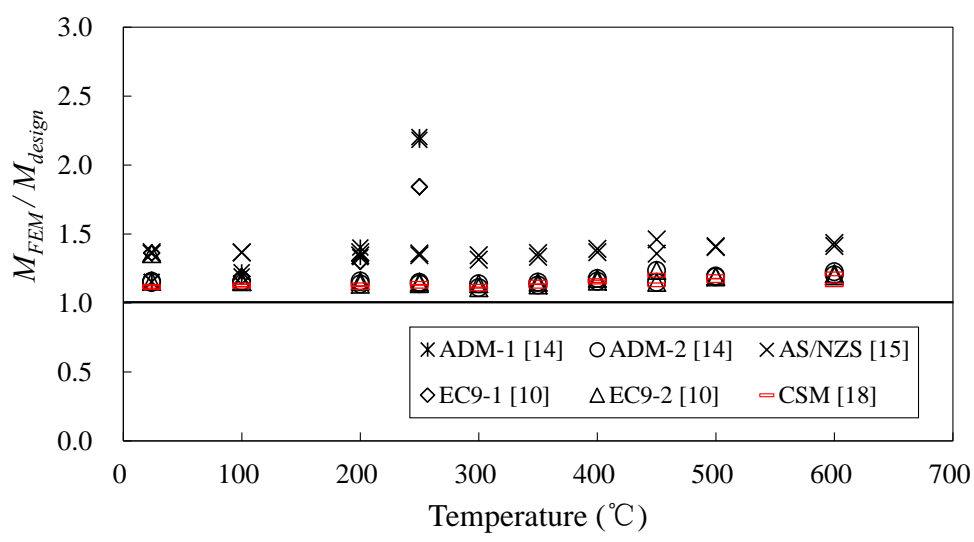

(c) $b / t=18$ 


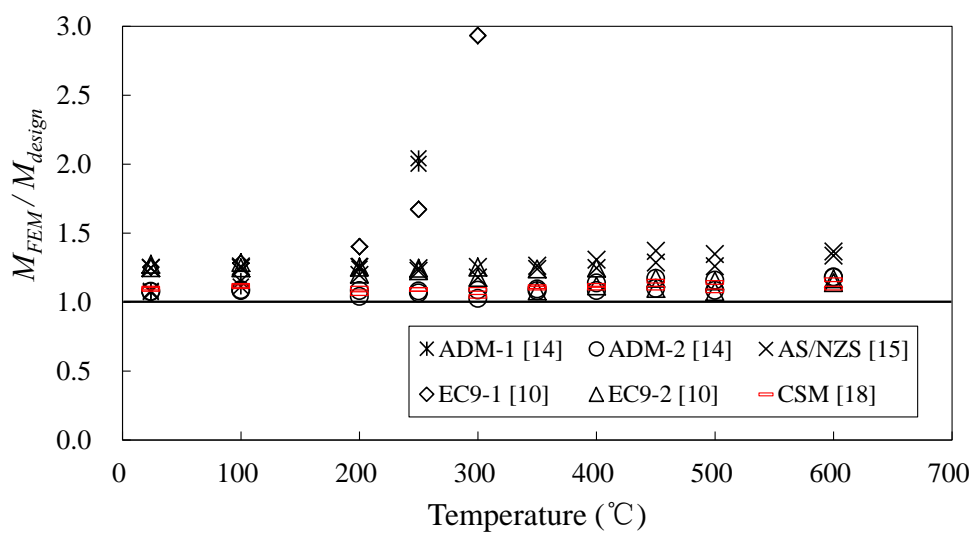

(d) $b / t=23$

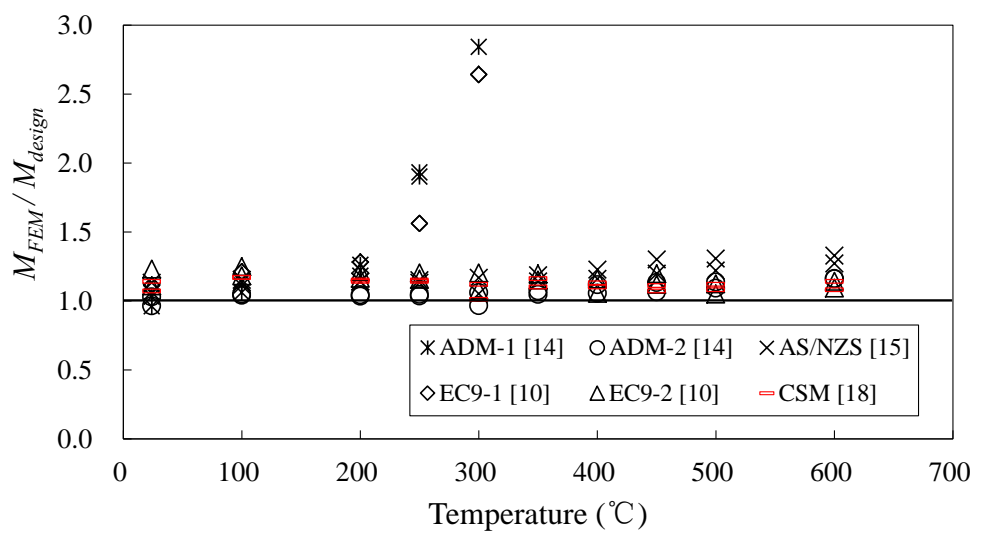

(e) $b / t=28$

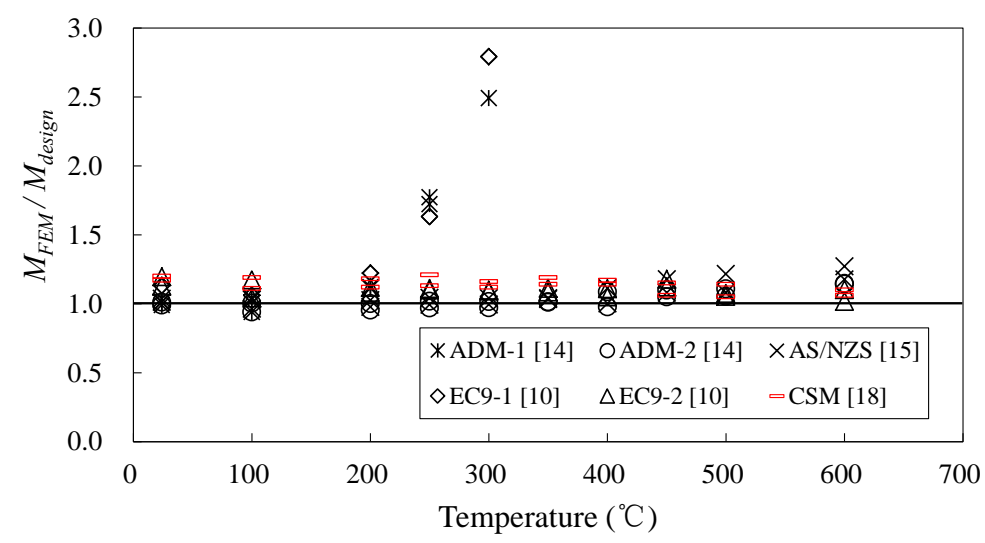

(f) $b / t=38$

Fig. 5. Comparison of numerical results and design strengths against temperatures 
Table. 1 Measured dimensions and material properties of beam specimens [9]

\begin{tabular}{cccccccccc}
\hline Specimens & $\begin{array}{c}B \\
(\mathrm{~mm})\end{array}$ & $\begin{array}{c}H \\
(\mathrm{~mm})\end{array}$ & $\begin{array}{c}t \\
(\mathrm{~mm})\end{array}$ & $\begin{array}{c}L \\
(\mathrm{~mm})\end{array}$ & $\begin{array}{c}D \\
(\mathrm{~mm})\end{array}$ & $\begin{array}{c}f_{y} \\
(\mathrm{MPa})\end{array}$ & $\begin{array}{c}f_{u} \\
(\mathrm{MPa})\end{array}$ & $\begin{array}{c}T \\
\left({ }^{\circ} \mathrm{C}\right)\end{array}$ & $\begin{array}{c}P_{\exp } \\
(\mathrm{kN})\end{array}$ \\
\hline 133A & 99.86 & 99.85 & 2.95 & 2000 & 149 & 69.6 & 74.1 & 300 & 4.13 \\
$134 \mathrm{~A}$ & 99.94 & 99.92 & 2.95 & 2000 & 152 & 119.7 & 124.1 & 250 & 9.13 \\
$141 \mathrm{~A}$ & 99.91 & 99.99 & 4.02 & 2000 & 146 & 52.2 & 66.8 & 300 & 5.60 \\
141B & 99.91 & 99.99 & 4.02 & 2000 & 146 & 86.8 & 108.2 & 250 & 10.75 \\
$145 \mathrm{~A}$ & 99.91 & 99.99 & 4.02 & 1000 & 146 & 86.8 & 108.2 & 250 & 19.82 \\
$151 \mathrm{~A}$ & 100.01 & 100.03 & 4.81 & 2000 & 152 & 64.3 & 66.2 & 300 & 7.07 \\
154A & 100.03 & 100.00 & 4.80 & 1000 & 150 & 117.9 & 125.2 & 250 & 25.33 \\
154B & 100.02 & 100.01 & 4.81 & 2000 & 158 & 117.9 & 125.2 & 250 & 12.45 \\
\hline
\end{tabular}


Table. 2 Material properties at elevated temperatures from tensile coupon tests [24]

\begin{tabular}{ccccc}
\hline $\begin{array}{c}\text { Aluminium } \\
\text { alloys }\end{array}$ & $\begin{array}{c}\text { Temperature } \\
\left({ }^{\circ} \mathrm{C}\right)\end{array}$ & $\begin{array}{c}E \\
(\mathrm{MPa})\end{array}$ & $\begin{array}{c}f_{y} \\
(\mathrm{MPa})\end{array}$ & $\begin{array}{c}f_{u} \\
(\mathrm{MPa})\end{array}$ \\
\hline \multirow{6}{*}{$6061-\mathrm{T} 6$} & 24 & 69500 & 199.9 & 232.3 \\
& 100 & 64018 & 195.2 & 225.1 \\
& 200 & 63350 & 176.9 & 197.8 \\
& 250 & 59410 & 176.0 & 190.8 \\
& 300 & 58502 & 181.0 & 189.1 \\
& 350 & 55086 & 164.0 & 169.6 \\
& 400 & 52100 & 139.0 & 145.9 \\
& 450 & 54200 & 105.1 & 108.4 \\
& 500 & 43100 & 80.7 & 85.1 \\
& 600 & 15700 & 17.5 & 20.6 \\
\hline \multirow{6}{*}{$6063-\mathrm{T5}$} & 24 & 65600 & 186.6 & 226.8 \\
& 100 & 63350 & 183.7 & 217.6 \\
& 200 & 56100 & 163.1 & 183.4 \\
& 250 & 54200 & 147.1 & 159.3 \\
& 300 & 51700 & 131.2 & 138.5 \\
& 350 & 47300 & 111.9 & 114.2 \\
& 400 & 33700 & 67.9 & 71.0 \\
& 450 & 43980 & 47.0 & 50.6 \\
& 500 & 34100 & 18.6 & 19.1 \\
& 600 & 28900 & 7.3 & 7.6 \\
\hline
\end{tabular}


Table 3. Comparison between experimental [14] and numerical results of three-point bending beams

\begin{tabular}{cccc}
\hline Specimens & $P_{\text {exp }}(\mathrm{kN})$ & $P_{F E M}(\mathrm{kN})$ & $\frac{F_{\text {exp }}}{F_{F E M}}$ \\
\hline $133 \mathrm{~A}$ & 4.13 & 4.19 & 0.99 \\
$134 \mathrm{~A}$ & 9.13 & 8.95 & 1.02 \\
$141 \mathrm{~A}$ & 5.60 & 5.98 & 0.94 \\
$141 \mathrm{~B}$ & 10.75 & 12.09 & 0.89 \\
$145 \mathrm{~A}$ & 19.82 & 20.80 & 0.95 \\
$151 \mathrm{~A}$ & 7.07 & 7.52 & 0.94 \\
$154 \mathrm{~A}$ & 25.33 & 25.09 & 1.01 \\
$154 \mathrm{~B}$ & 12.45 & 14.57 & 0.85 \\
\hline & & Mean & 0.95 \\
& & $\mathrm{CoV}$ & 0.053 \\
\hline
\end{tabular}


Table 4. Comparisons between test results [14] and design strengths

\begin{tabular}{lcccccccc}
\hline Specimens & $b / t$ & - & $\frac{M_{\text {exp }}}{M_{A D M-1}}$ & $\frac{M_{\text {exp }}}{M_{A D M-2}}$ & $\frac{M_{\text {exp }}}{M_{A S / N Z S}}$ & $\frac{M_{\text {exp }}}{M_{E C 9-1}}$ & $\frac{M_{\text {exp }}}{M_{E C 9-2}}$ & $\frac{M_{\text {exp }}}{M_{C S M}}$ \\
\hline 133A & 31.9 & 0.56 & 0.78 & 0.75 & 0.83 & 1.02 & 0.83 & 0.61 \\
134A & 31.9 & 0.69 & 1.00 & 0.98 & 1.06 & 1.31 & 1.06 & 1.07 \\
141A & 22.9 & 0.35 & 0.89 & 0.97 & 1.13 & 1.22 & 0.97 & 0.91 \\
141B & 22.9 & 0.42 & 0.97 & 1.11 & 1.31 & 1.17 & 1.12 & 1.08 \\
145A & 22.9 & 0.42 & 0.89 & 1.03 & 1.20 & 1.08 & 1.03 & 1.00 \\
151A & 18.8 & 0.33 & 0.93 & 0.84 & 0.99 & 1.28 & 0.84 & 0.83 \\
154A & 18.8 & 0.41 & 0.95 & 0.82 & 0.97 & 1.15 & 0.82 & 0.81 \\
154B & 18.8 & 0.41 & 0.93 & 0.81 & 0.95 & 1.13 & 0.81 & 0.80 \\
\hline
\end{tabular}


Table 5. Comparisons between numerical results and design strengths (aluminium alloy 6061-T6)

\begin{tabular}{|c|c|c|c|c|c|c|c|c|c|}
\hline Specimens & $b / t$ & - & $M_{F E M}$ & $\frac{M_{F E M}}{M_{A D M-1}}$ & $\frac{M_{F E M}}{M_{A D M-2}}$ & $\frac{M_{F E M}}{M_{A S / N Z S}}$ & $\frac{M_{F E M}}{M_{E C 9-1}}$ & $\frac{M_{F E M}}{M_{E C 9-2}}$ & $\frac{M_{F E M}}{M_{C S M}}$ \\
\hline $\mathrm{H} 100 \times 100 \times 10-\mathrm{T} 24$ & 8.0 & 0.21 & 35.81 & 1.46 & 1.46 & 1.82 & 1.47 & 1.47 & 1.30 \\
\hline $\mathrm{H} 100 \times 100 \times 10-\mathrm{T} 100$ & 8.0 & 0.21 & 35.22 & 1.52 & 1.47 & 1.83 & 1.52 & 1.48 & 1.32 \\
\hline $\mathrm{H} 100 \times 100 \times 10-\mathrm{T} 200$ & 8.0 & 0.20 & 31.48 & 1.67 & 1.45 & 1.81 & 1.63 & 1.46 & 1.33 \\
\hline $\mathrm{H} 100 \times 100 \times 10-\mathrm{T} 250$ & 8.0 & 0.21 & 30.79 & 2.74 & 1.43 & 1.78 & 2.30 & 1.43 & 1.34 \\
\hline $\mathrm{H} 100 \times 100 \times 10-\mathrm{T} 300$ & 8.0 & 0.21 & 30.95 & 4.87 & 1.40 & 1.74 & 4.09 & 1.40 & 1.35 \\
\hline $\mathrm{H} 100 \times 100 \times 10-\mathrm{T} 350$ & 8.0 & 0.21 & 27.77 & 8.74 & 1.38 & 1.72 & 11.39 & 1.39 & 1.35 \\
\hline $\mathrm{H} 100 \times 100 \times 10-\mathrm{T} 400$ & 8.0 & 0.20 & 23.94 & 13.98 & 1.41 & 1.75 & 13.09 & 1.41 & 1.36 \\
\hline $\mathrm{H} 100 \times 100 \times 10-\mathrm{T} 450$ & 8.0 & 0.17 & 17.84 & 18.32 & 1.39 & 1.73 & 14.63 & 1.39 & 1.36 \\
\hline $\mathrm{H} 100 \times 100 \times 10-\mathrm{T} 500$ & 8.0 & 0.17 & 14.05 & 29.07 & 1.42 & 1.77 & 23.05 & 1.43 & 1.38 \\
\hline $\mathrm{H} 100 \times 100 \times 10-\mathrm{T} 600$ & 8.0 & 0.13 & 3.30 & - & 1.54 & 1.91 & - & 1.54 & 1.46 \\
\hline $\mathrm{H} 100 \times 100 \times 6.67-\mathrm{T} 24$ & 13.0 & 0.33 & 22.02 & 1.26 & 1.26 & 1.52 & 1.26 & 1.26 & 1.12 \\
\hline $\mathrm{H} 100 \times 100 \times 6.67-\mathrm{T} 100$ & 13.0 & 0.34 & 21.63 & 1.30 & 1.27 & 1.52 & 1.30 & 1.27 & 1.14 \\
\hline H100×100×6.67-T200 & 13.0 & 0.33 & 19.55 & 1.45 & 1.26 & 1.52 & 1.42 & 1.27 & 1.15 \\
\hline $\mathrm{H} 100 \times 100 \times 6.67-\mathrm{T} 250$ & 13.0 & 0.34 & 19.25 & 2.40 & 1.25 & 1.51 & 2.01 & 1.25 & 1.17 \\
\hline H100×100×6.67-T300 & 13.0 & 0.35 & 19.54 & 4.30 & 1.24 & 1.49 & 3.61 & 1.24 & 1.19 \\
\hline H100×100×6.67-Т350 & 13.0 & 0.34 & 17.58 & 7.74 & 1.23 & 1.47 & 10.07 & 1.23 & 1.20 \\
\hline H100×100×6.67-T400 & 13.0 & 0.32 & 15.19 & 12.43 & 1.25 & 1.50 & 11.60 & 1.25 & 1.20 \\
\hline $\mathrm{H} 100 \times 100 \times 6.67-\mathrm{T} 450$ & 13.0 & 0.28 & 11.49 & 16.57 & 1.25 & 1.50 & 13.17 & 1.25 & 1.22 \\
\hline $\mathrm{H} 100 \times 100 \times 6.67-\mathrm{T} 500$ & 13.0 & 0.27 & 9.00 & 26.16 & 1.28 & 1.53 & 20.62 & 1.28 & 1.23 \\
\hline H100×100×6.67-T600 & 13.0 & 0.21 & 1.96 & - & 1.28 & 1.54 & - & 1.28 & 1.21 \\
\hline $\mathrm{H} 100 \times 100 \times 5-\mathrm{T} 24$ & 18.0 & 0.46 & 15.52 & 1.15 & 1.15 & 1.36 & 1.36 & 1.36 & 1.12 \\
\hline $\mathrm{H} 100 \times 100 \times 5-\mathrm{T} 100$ & 18.0 & 0.48 & 15.27 & 1.19 & 1.15 & 1.36 & 1.19 & 1.15 & 1.13 \\
\hline $\mathrm{H} 100 \times 100 \times 5-\mathrm{T} 200$ & 18.0 & 0.46 & 13.86 & 1.33 & 1.16 & 1.37 & 1.30 & 1.16 & 1.13 \\
\hline $\mathrm{H} 100 \times 100 \times 5-\mathrm{T} 250$ & 18.0 & 0.47 & 13.69 & 2.20 & 1.15 & 1.36 & 1.84 & 1.15 & 1.14 \\
\hline $\mathrm{H} 100 \times 100 \times 5-\mathrm{T} 300$ & 18.0 & 0.48 & 13.60 & 3.86 & 1.11 & 1.31 & 3.24 & 1.11 & 1.10 \\
\hline $\mathrm{H} 100 \times 100 \times 5-\mathrm{T} 350$ & 18.0 & 0.47 & 12.54 & 7.12 & 1.13 & 1.33 & 9.26 & 1.13 & 1.12 \\
\hline $\mathrm{H} 100 \times 100 \times 5-\mathrm{T} 400$ & 18.0 & 0.45 & 10.89 & 11.53 & 1.16 & 1.37 & 10.72 & 1.16 & 1.15 \\
\hline $\mathrm{H} 100 \times 100 \times 5-\mathrm{T} 450$ & 18.0 & 0.38 & 8.17 & 15.24 & 1.15 & 1.36 & 12.06 & 1.15 & 1.13 \\
\hline $\mathrm{H} 100 \times 100 \times 5-\mathrm{T} 500$ & 18.0 & 0.37 & 6.49 & 24.42 & 1.19 & 1.40 & 19.17 & 1.19 & 1.16 \\
\hline $\mathrm{H} 100 \times 100 \times 5-\mathrm{T} 600$ & 18.0 & 0.29 & 1.42 & - & 1.20 & 1.41 & - & 1.19 & 1.13 \\
\hline $\mathrm{H} 100 \times 100 \times 4-\mathrm{T} 24$ & 23.0 & 0.59 & 11.79 & 1.08 & 1.08 & 1.25 & 1.25 & 1.25 & 1.10 \\
\hline $\mathrm{H} 100 \times 100 \times 4-\mathrm{T} 100$ & 23.0 & 0.61 & 11.50 & 1.11 & 1.08 & 1.25 & 1.28 & 1.25 & 1.12 \\
\hline $\mathrm{H} 100 \times 100 \times 4-\mathrm{T} 200$ & 23.0 & 0.58 & 10.47 & 1.24 & 1.08 & 1.25 & 1.40 & 1.25 & 1.10 \\
\hline $\mathrm{H} 100 \times 100 \times 4-\mathrm{T} 250$ & 23.0 & 0.60 & 10.19 & 2.00 & 1.06 & 1.22 & 1.67 & 1.22 & 1.09 \\
\hline
\end{tabular}


Table 5. (cont'd)

\begin{tabular}{|c|c|c|c|c|c|c|c|c|c|}
\hline \multirow{2}{*}{ Specimen } & \multirow{2}{*}{$b / t$} & \multirow{2}{*}{-} & \multirow{2}{*}{$M_{F E M}$} & \multirow{2}{*}{$\frac{M_{F E M}}{M_{A D M-1}}$} & \multirow{2}{*}{$\frac{M_{F E M}}{M_{A D M-2}}$} & \multirow{2}{*}{$\frac{M_{F E M}}{M_{A S / N Z S}}$} & \multirow{2}{*}{$\frac{M_{F E M}}{M_{E C 9-1}}$} & \multirow{2}{*}{$\frac{M_{F E M}}{M_{E C 9-2}}$} & \multirow{2}{*}{$\frac{M_{F E M}}{M_{C S M}}$} \\
\hline & & & & & & & & & \\
\hline H100×100×4-T300 & 23.0 & 0.61 & 10.06 & 3.50 & 1.03 & 1.18 & 2.93 & 1.18 & 1.04 \\
\hline H100×100×4-T350 & 23.0 & 0.60 & 9.61 & 6.68 & 1.08 & 1.24 & 8.69 & 1.24 & 1.11 \\
\hline H100×100×4-T400 & 23.0 & 0.57 & 8.18 & 10.64 & 1.08 & 1.25 & 9.86 & 1.25 & 1.10 \\
\hline $\mathrm{H} 100 \times 100 \times 4-\mathrm{T} 450$ & 23.0 & 0.49 & 6.38 & 14.62 & 1.10 & 1.28 & 11.53 & 1.10 & 1.10 \\
\hline $\mathrm{H} 100 \times 100 \times 4-\mathrm{T} 500$ & 23.0 & 0.48 & 4.80 & 22.41 & 1.08 & 1.26 & 17.36 & 1.08 & 1.08 \\
\hline H100×100×4-T600 & 23.0 & 0.37 & 1.11 & - & 1.18 & 1.33 & - & 1.14 & 1.10 \\
\hline $\mathrm{H} 100 \times 100 \times 3.33-\mathrm{T} 24$ & 28.0 & 0.72 & 8.52 & 0.96 & 0.96 & 1.06 & 1.11 & 1.11 & 1.07 \\
\hline $\mathrm{H} 100 \times 100 \times 3.33-\mathrm{T} 100$ & 28.0 & 0.74 & 8.90 & 1.06 & 1.04 & 1.14 & 1.21 & 1.18 & 1.17 \\
\hline $\mathrm{H} 100 \times 100 \times 3.33-\mathrm{T} 200$ & 28.0 & 0.71 & 8.09 & 1.18 & 1.03 & 1.14 & 1.28 & 1.16 & 1.14 \\
\hline $\mathrm{H} 100 \times 100 \times 3.33-\mathrm{T} 250$ & 28.0 & 0.73 & 7.99 & 1.90 & 1.03 & 1.13 & 1.56 & 1.15 & 1.15 \\
\hline $\mathrm{H} 100 \times 100 \times 3.33-\mathrm{T} 300$ & 28.0 & 0.75 & 7.63 & 3.17 & 0.96 & 1.05 & 2.64 & 1.08 & 1.01 \\
\hline $\mathrm{H} 100 \times 100 \times 3.33-\mathrm{T} 350$ & 28.0 & 0.74 & 7.50 & 6.21 & 1.05 & 1.14 & 8.04 & 1.15 & 1.16 \\
\hline $\mathrm{H} 100 \times 100 \times 3.33-\mathrm{T} 400$ & 28.0 & 0.70 & 6.46 & 10.00 & 1.05 & 1.16 & 9.23 & 1.16 & 1.13 \\
\hline $\mathrm{H} 100 \times 100 \times 3.33-\mathrm{T} 450$ & 28.0 & 0.59 & 5.05 & 13.84 & 1.06 & 1.20 & 10.82 & 1.20 & 1.07 \\
\hline $\mathrm{H} 100 \times 100 \times 3.33-\mathrm{T} 500$ & 28.0 & 0.58 & 3.95 & 22.24 & 1.09 & 1.22 & 16.93 & 1.05 & 1.08 \\
\hline $\mathrm{H} 100 \times 100 \times 3.33-\mathrm{T} 600$ & 28.0 & 0.45 & 0.89 & - & 1.16 & 1.27 & - & 1.09 & 1.08 \\
\hline $\mathrm{H} 100 \times 100 \times 2.5-\mathrm{T} 24$ & 38.0 & 0.98 & 5.94 & 0.99 & 0.99 & 1.01 & 1.13 & 1.13 & 1.17 \\
\hline $\mathrm{H} 100 \times 100 \times 2.5-\mathrm{T} 100$ & 38.0 & 1.01 & 5.39 & 0.94 & 0.94 & 0.96 & 1.06 & 1.04 & 1.11 \\
\hline $\mathrm{H} 100 \times 100 \times 2.5-\mathrm{T} 200$ & 38.0 & 0.97 & 5.34 & 1.12 & 1.00 & 1.02 & 1.22 & 1.12 & 1.18 \\
\hline $\mathrm{H} 100 \times 100 \times 2.5-\mathrm{T} 250$ & 38.0 & 0.99 & 5.28 & 1.77 & 1.02 & 1.04 & 1.63 & 1.11 & 1.21 \\
\hline $\mathrm{H} 100 \times 100 \times 2.5-\mathrm{T} 300$ & 38.0 & 1.02 & 5.34 & 3.07 & 1.01 & 1.04 & 2.79 & 1.10 & 1.16 \\
\hline $\mathrm{H} 100 \times 100 \times 2.5-\mathrm{T} 350$ & 38.0 & 1.00 & 4.88 & 5.51 & 1.01 & 1.04 & 6.85 & 1.08 & 1.19 \\
\hline $\mathrm{H} 100 \times 100 \times 2.5-\mathrm{T} 400$ & 38.0 & 0.94 & 4.12 & 8.64 & 0.98 & 1.00 & 7.71 & 1.05 & 1.14 \\
\hline $\mathrm{H} 100 \times 100 \times 2.5-\mathrm{T} 450$ & 38.0 & 0.80 & 3.50 & 12.98 & 1.05 & 1.08 & 9.83 & 1.12 & 1.15 \\
\hline $\mathrm{H} 100 \times 100 \times 2.5-\mathrm{T} 500$ & 38.0 & 0.79 & 2.68 & 20.42 & 1.05 & 1.08 & 15.02 & 1.07 & 1.14 \\
\hline $\mathrm{H} 100 \times 100 \times 2.5-\mathrm{T} 600$ & 38.0 & 0.61 & 0.64 & - & 1.14 & 1.17 & - & 1.02 & 1.06 \\
\hline
\end{tabular}


Table 6. Comparisons between numerical results with design strengths (aluminium alloy

6063-T5)

\begin{tabular}{|c|c|c|c|c|c|c|c|c|c|}
\hline Specimens & $b / t$ & - & $M_{F E M}$ & $\frac{M_{F E M}}{M_{A D M-1}}$ & $\frac{M_{F E M}}{M_{A D M-2}}$ & $\frac{M_{F E M}}{M_{A S / N Z S}}$ & $\frac{M_{F E M}}{M_{E C 9-1}}$ & $\frac{M_{F E M}}{M_{E C 9-2}}$ & $\frac{M_{F E M}}{M_{C S M}}$ \\
\hline $\mathrm{N} 100 \times 100 \times 10-\mathrm{T} 24$ & 8.0 & 0.22 & 34.69 & 1.52 & 1.52 & 1.89 & 1.47 & 1.52 & 1.30 \\
\hline $\mathrm{N} 100 \times 100 \times 10-\mathrm{T} 100$ & 8.0 & 0.22 & 33.53 & 1.58 & 1.49 & 1.85 & 1.52 & 1.50 & 1.30 \\
\hline $\mathrm{N} 100 \times 100 \times 10-\mathrm{T} 200$ & 8.0 & 0.22 & 29.23 & 1.80 & 1.46 & 1.82 & 1.63 & 1.47 & 1.34 \\
\hline $\mathrm{N} 100 \times 100 \times 10-\mathrm{T} 250$ & 8.0 & 0.22 & 25.84 & 2.76 & 1.44 & 1.79 & 2.30 & 1.44 & 1.35 \\
\hline $\mathrm{N} 100 \times 100 \times 10-\mathrm{T} 300$ & 8.0 & 0.21 & 22.70 & 3.98 & 1.41 & 1.76 & 4.09 & 1.42 & 1.36 \\
\hline $\mathrm{N} 100 \times 100 \times 10-\mathrm{T} 350$ & 8.0 & 0.20 & 18.71 & 6.30 & 1.37 & 1.70 & 11.39 & 1.37 & 1.35 \\
\hline $\mathrm{N} 100 \times 100 \times 10-\mathrm{T} 400$ & 8.0 & 0.19 & 11.73 & 7.34 & 1.41 & 1.76 & 13.09 & 1.42 & 1.37 \\
\hline $\mathrm{N} 100 \times 100 \times 10-\mathrm{T} 450$ & 8.0 & 0.14 & 8.35 & 9.19 & 1.45 & 1.80 & 14.63 & 1.46 & 1.42 \\
\hline $\mathrm{N} 100 \times 100 \times 10-\mathrm{T} 500$ & 8.0 & 0.10 & 3.20 & 7.10 & 1.41 & 1.75 & 23.05 & 1.41 & 1.40 \\
\hline $\mathrm{N} 100 \times 100 \times 10-\mathrm{T} 600$ & 8.0 & 0.07 & 1.28 & - & 1.44 & 1.78 & - & 1.44 & 1.43 \\
\hline $\mathrm{N} 100 \times 100 \times 6.67-\mathrm{T} 24$ & 13.0 & 0.34 & 21.07 & 1.29 & 1.29 & 1.55 & 1.26 & 1.29 & 1.12 \\
\hline $\mathrm{N} 100 \times 100 \times 6.67-\mathrm{T} 100$ & 13.0 & 0.34 & 20.08 & 1.32 & 1.25 & 1.50 & 1.30 & 1.25 & 1.10 \\
\hline $\mathrm{N} 100 \times 100 \times 6.67-\mathrm{T} 200$ & 13.0 & 0.34 & 17.90 & 1.55 & 1.26 & 1.51 & 1.42 & 1.26 & 1.14 \\
\hline $\mathrm{N} 100 \times 100 \times 6.67-\mathrm{T} 250$ & 13.0 & 0.33 & 16.21 & 2.42 & 1.26 & 1.52 & 2.01 & 1.26 & 1.18 \\
\hline $\mathrm{N} 100 \times 100 \times 6.67-\mathrm{T} 300$ & 13.0 & 0.32 & 14.24 & 3.49 & 1.24 & 1.49 & 3.61 & 1.24 & 1.19 \\
\hline $\mathrm{N} 100 \times 100 \times 6.67-\mathrm{T} 350$ & 13.0 & 0.31 & 11.99 & 5.66 & 1.23 & 1.47 & 10.07 & 1.23 & 1.21 \\
\hline $\mathrm{N} 100 \times 100 \times 6.67-\mathrm{T} 400$ & 13.0 & 0.28 & 7.52 & 6.60 & 1.27 & 1.52 & 11.60 & 1.27 & 1.23 \\
\hline $\mathrm{N} 100 \times 100 \times 6.67-\mathrm{T} 450$ & 13.0 & 0.21 & 5.40 & 8.35 & 1.31 & 1.58 & 13.17 & 1.32 & 1.28 \\
\hline $\mathrm{N} 100 \times 100 \times 6.67-\mathrm{T} 500$ & 13.0 & 0.15 & 2.05 & 6.40 & 1.26 & 1.52 & 20.62 & 1.26 & 1.26 \\
\hline N100×100×6.67-T600 & 13.0 & 0.10 & 0.82 & - & 1.30 & 1.55 & - & 1.29 & 1.29 \\
\hline $\mathrm{N} 100 \times 100 \times 5-\mathrm{T} 24$ & 18.0 & 0.45 & 14.61 & 1.15 & 1.15 & 1.37 & 1.36 & 1.16 & 1.11 \\
\hline $\mathrm{N} 100 \times 100 \times 5-\mathrm{T} 100$ & 18.0 & 0.46 & 14.36 & 1.22 & 1.15 & 1.36 & 1.19 & 1.15 & 1.12 \\
\hline $\mathrm{N} 100 \times 100 \times 5-\mathrm{T} 200$ & 18.0 & 0.46 & 12.54 & 1.40 & 1.13 & 1.34 & 1.30 & 1.13 & 1.11 \\
\hline $\mathrm{N} 100 \times 100 \times 5-\mathrm{T} 250$ & 18.0 & 0.44 & 11.33 & 2.18 & 1.14 & 1.34 & 1.84 & 1.14 & 1.12 \\
\hline $\mathrm{N} 100 \times 100 \times 5-\mathrm{T} 300$ & 18.0 & 0.43 & 10.11 & 3.20 & 1.14 & 1.34 & 3.24 & 1.14 & 1.12 \\
\hline $\mathrm{N} 100 \times 100 \times 5-\mathrm{T} 350$ & 18.0 & 0.41 & 8.71 & 5.30 & 1.15 & 1.36 & 9.26 & 1.15 & 1.15 \\
\hline $\mathrm{N} 100 \times 100 \times 5-\mathrm{T} 400$ & 18.0 & 0.38 & 5.41 & 6.14 & 1.17 & 1.39 & 10.72 & 1.18 & 1.16 \\
\hline $\mathrm{N} 100 \times 100 \times 5-\mathrm{T} 450$ & 18.0 & 0.28 & 3.93 & 7.85 & 1.23 & 1.46 & 12.06 & 1.23 & 1.20 \\
\hline $\mathrm{N} 100 \times 100 \times 5-\mathrm{T} 500$ & 18.0 & 0.20 & 1.50 & 6.06 & 1.19 & 1.41 & 19.17 & 1.19 & 1.19 \\
\hline $\mathrm{N} 100 \times 100 \times 5-\mathrm{T} 600$ & 18.0 & 0.14 & 0.60 & - & 1.22 & 1.43 & - & 1.21 & 1.21 \\
\hline $\mathrm{N} 100 \times 100 \times 4-\mathrm{T} 24$ & 23.0 & 0.57 & 10.96 & 1.07 & 1.07 & 1.24 & 1.25 & 1.27 & 1.09 \\
\hline $\mathrm{N} 100 \times 100 \times 4-\mathrm{T} 100$ & 23.0 & 0.58 & 10.92 & 1.15 & 1.09 & 1.26 & 1.28 & 1.28 & 1.11 \\
\hline $\mathrm{N} 100 \times 100 \times 4-\mathrm{T} 200$ & 23.0 & 0.58 & 9.20 & 1.26 & 1.04 & 1.19 & 1.40 & 1.20 & 1.06 \\
\hline $\mathrm{N} 100 \times 100 \times 4-\mathrm{T} 250$ & 23.0 & 0.56 & 8.64 & 2.04 & 1.08 & 1.24 & 1.67 & 1.24 & 1.09 \\
\hline
\end{tabular}


Table 6. (cont'd)

\begin{tabular}{|c|c|c|c|c|c|c|c|c|c|}
\hline Specimens & $b / t$ & - & $M_{F E M}$ & $\frac{M_{F E M}}{M_{A D M-1}}$ & $\frac{M_{F E M}}{M_{A D M-2}}$ & $\frac{M_{F E M}}{M_{A S / N Z S}}$ & $\frac{M_{F E M}}{M_{E C 9-1}}$ & $\frac{M_{F E M}}{M_{E C 9-2}}$ & $\frac{M_{F E M}}{M_{C S M}}$ \\
\hline $\mathrm{N} 100 \times 100 \times 4-\mathrm{T} 300$ & 23.0 & 0.54 & 7.77 & 3.01 & 1.09 & 1.25 & 2.93 & 1.25 & 1.09 \\
\hline $\mathrm{N} 100 \times 100 \times 4-\mathrm{T} 350$ & 23.0 & 0.52 & 6.67 & 4.98 & 1.09 & 1.26 & 8.69 & 1.08 & 1.10 \\
\hline $\mathrm{N} 100 \times 100 \times 4-\mathrm{T} 400$ & 23.0 & 0.48 & 4.19 & 5.84 & 1.14 & 1.31 & 9.86 & 1.12 & 1.12 \\
\hline $\mathrm{N} 100 \times 100 \times 4-\mathrm{T} 450$ & 23.0 & 0.35 & 3.04 & 7.48 & 1.17 & 1.37 & 11.53 & 1.17 & 1.15 \\
\hline $\mathrm{N} 100 \times 100 \times 4-\mathrm{T} 500$ & 23.0 & 0.26 & 1.18 & 5.87 & 1.16 & 1.35 & 17.36 & 1.15 & 1.14 \\
\hline N100×100×4-T600 & 23.0 & 0.17 & 0.47 & - & 1.18 & 1.36 & - & 1.17 & 1.16 \\
\hline $\mathrm{N} 100 \times 100 \times 3.33-\mathrm{T} 24$ & 28.0 & 0.69 & 8.47 & 1.03 & 1.03 & 1.13 & 1.11 & 1.23 & 1.14 \\
\hline $\mathrm{N} 100 \times 100 \times 3.33-\mathrm{T} 100$ & 28.0 & 0.70 & 8.49 & 1.11 & 1.05 & 1.15 & 1.21 & 1.25 & 1.17 \\
\hline $\mathrm{N} 100 \times 100 \times 3.33-\mathrm{T} 200$ & 28.0 & 0.70 & 7.47 & 1.26 & 1.04 & 1.14 & 1.28 & 1.21 & 1.15 \\
\hline $\mathrm{N} 100 \times 100 \times 3.33-\mathrm{T} 250$ & 28.0 & 0.67 & 6.78 & 1.93 & 1.05 & 1.15 & 1.56 & 1.20 & 1.14 \\
\hline $\mathrm{N} 100 \times 100 \times 3.33-\mathrm{T} 300$ & 28.0 & 0.65 & 6.14 & 2.84 & 1.06 & 1.17 & 2.64 & 1.20 & 1.12 \\
\hline $\mathrm{N} 100 \times 100 \times 3.33-\mathrm{T} 350$ & 28.0 & 0.63 & 5.32 & 4.72 & 1.07 & 1.18 & 8.04 & 1.19 & 1.10 \\
\hline $\mathrm{N} 100 \times 100 \times 3.33-\mathrm{T} 400$ & 28.0 & 0.58 & 3.34 & 5.54 & 1.11 & 1.23 & 9.23 & 1.05 & 1.10 \\
\hline $\mathrm{N} 100 \times 100 \times 3.33-\mathrm{T} 450$ & 28.0 & 0.42 & 2.45 & 7.21 & 1.13 & 1.30 & 10.82 & 1.12 & 1.11 \\
\hline $\mathrm{N} 100 \times 100 \times 3.33-\mathrm{T} 500$ & 28.0 & 0.31 & 0.97 & 5.88 & 1.13 & 1.31 & 16.93 & 1.12 & 1.12 \\
\hline $\mathrm{N} 100 \times 100 \times 3.33-\mathrm{T} 600$ & 28.0 & 0.21 & 0.39 & - & 1.16 & 1.33 & - & 1.14 & 1.14 \\
\hline $\mathrm{N} 100 \times 100 \times 2.5-\mathrm{T} 24$ & 38.0 & 0.93 & 5.67 & 1.01 & 1.01 & 1.04 & 1.13 & 1.19 & 1.20 \\
\hline $\mathrm{N} 100 \times 100 \times 2.5-\mathrm{T} 100$ & 38.0 & 0.94 & 5.50 & 1.04 & 1.00 & 1.03 & 1.06 & 1.17 & 1.19 \\
\hline $\mathrm{N} 100 \times 100 \times 2.5-\mathrm{T} 200$ & 38.0 & 0.94 & 4.60 & 1.11 & 0.95 & 0.98 & 1.22 & 1.08 & 1.12 \\
\hline $\mathrm{N} 100 \times 100 \times 2.5-\mathrm{T} 250$ & 38.0 & 0.91 & 4.30 & 1.72 & 0.97 & 0.99 & 1.63 & 1.10 & 1.13 \\
\hline $\mathrm{N} 100 \times 100 \times 2.5-\mathrm{T} 300$ & 38.0 & 0.88 & 3.89 & 2.49 & 0.97 & 0.99 & 2.79 & 1.09 & 1.12 \\
\hline $\mathrm{N} 100 \times 100 \times 2.5-\mathrm{T} 350$ & 38.0 & 0.85 & 3.47 & 4.20 & 1.01 & 1.03 & 6.85 & 1.11 & 1.14 \\
\hline $\mathrm{N} 100 \times 100 \times 2.5-\mathrm{T} 400$ & 38.0 & 0.78 & 2.27 & 5.11 & 1.08 & 1.11 & 7.71 & 1.11 & 1.17 \\
\hline $\mathrm{N} 100 \times 100 \times 2.5-\mathrm{T} 450$ & 38.0 & 0.57 & 1.71 & 6.80 & 1.10 & 1.18 & 9.83 & 1.18 & 1.06 \\
\hline $\mathrm{N} 100 \times 100 \times 2.5-\mathrm{T} 500$ & 38.0 & 0.41 & 0.70 & 5.71 & 1.11 & 1.21 & 15.02 & 1.05 & 1.05 \\
\hline $\mathrm{N} 100 \times 100 \times 2.5-\mathrm{T} 600$ & 38.0 & 0.28 & 0.29 & - & 1.14 & 1.27 & - & 1.10 & 1.10 \\
\hline
\end{tabular}


Table 7 Summary comparison results and reliability analysis for design methods (number of specimens: 128)

\begin{tabular}{|c|c|c|c|c|c|c|}
\hline & $\frac{M_{u}}{M_{A D M-1}}$ & $\frac{M_{u}}{M_{A D M-2}}$ & $\frac{M_{u}}{M_{A S / N Z S}}$ & $\frac{M_{u}}{M_{E C 9-1}}$ & $\frac{M_{u}}{M_{E C 9-2}}$ & $\frac{M_{u}}{M_{c s m}}$ \\
\hline Mean, $P_{m}$ & 5.32 & 1.16 & 1.34 & 4.44 & 1.20 & 1.16 \\
\hline $\mathrm{CoV}, V_{p}$ & 5.877 & 0.158 & 0.250 & 4.686 & 0.139 & 0.121 \\
\hline$\varphi$ & 0.90 & 0.90 & 0.85 & 0.91 & 0.91 & 0.90 \\
\hline$\beta$ & 0.382 & 2.73 & 2.73 & 0.434 & 2.86 & 2.73 \\
\hline
\end{tabular}

